\title{
Resistivity Cross Section Through the Juan de Fuca Subduction System and Its Tectonic Implications
}

\author{
Phim E. Wannamaker, ${ }^{1}$ John R. Booker, ${ }^{2}$ Alan G. Jones, ${ }^{3}$ Alan D. Chave, ${ }^{4}$ \\ Jean H. Filloux ${ }^{5}$ Harve S. WafF, ${ }^{6}$ and Lawrie K. Law ${ }^{7}$
}

\begin{abstract}
A resistivity cross section to depths exceeding $200 \mathrm{~km}$ has been derived from magnetotelluric observations along a profile near latitude $45^{\circ} \mathrm{N}$ from the Juan de Fuca spreading center, across the coastal subduction complex, the High Cascades volcanic arc, and into the back-arc Deschutes Basin region. In this two-dimensional interpretation, emphasis was placed on data approximating the transverse magnetic mode since these data are relatively robust to common departures from the two-dimensional assumption. The vertical magnetic field, however, has been very valuable in defining structure of the offshore sediments, of the oceanic asthenosphere and below the arc volcanics of the Westem and High Cascades. The transverse electric data on land suffer a variety of three-dimensional effects, making their interpretation very difficult. In contrast, the greater uniformity of upper crustal conditions on the seafloor allowed a good fit to both modes of the impedance plus the vertical magnetic field at least down to $10^{4} \mathrm{~s}$. Important components of our model resistivity structure and their hypothesized tectonic implications are as follows. Measurements on the seafloor indicate very low resistivity in the eastward thickening sedimentary wedge of the abyssal Cascadia Basin provided its depth extent is constrained. The majority of these sediments are inferred to be off-scraped or lose most of their interstitial water before being carried more than ten or so kilometers down the trench. In the oceanic upper mantle of the Juan de Fuca plate, moderately low resistivities from about $35-215 \mathrm{~km}$ depth (nominal) presumably reflect up to several percent partial melt attending regional upwelling in the vicinity of the ridge. Very low resistivities below $215 \mathrm{~km}$ depth in the oceanic mantle are difficult to explain physically, but problems with very long-period source field effects or bias error may hamper the modeling here. Under the Oregon Coast Range, a low-resistivity layer dips inland at approximately $20^{\circ}$. Its conductance decreases by an order of magnitude from the coast to around $60 \mathrm{~km}$ inland and its position appears consistent with the Juan de Fuca plate subduction decollement. Possible causes of the low-resistivity include residual sediments, pore waters, perhaps sulfides, and dehydrating oceanic crust carried down the subduction zone. East of about $60 \mathrm{~km}$ inland, there is a much stronger, subhorizontal conductor with a depth to top of around $25 \mathrm{~km}$. To explain it, a massive breakdown of greenschist minerals is hypothesized to liberate most of the water carried in the altered ocean crust well before the volcanic arc is reached. The resistivity manifestation of the arc magmatism itself is not strong but consists of a low-resistivity axis in the middle crust below and to the west of the arc at the surface. It presumably represents fluids released from crystallizing magmas. East of the High Cascades, both the MT and geomagnetic data detect a strong gradient in resistivity with lower values to the south. It is suggested that the Brothers fault zone signifies an electrical, thus possibly a themal and magmatic, boundary with the northem Basin and Range.
\end{abstract}

\section{INTRODUCTION}

A magnetotelluric (MT) transect of unprecedented breadth and quality has been collected across the Juan de Fuca subduction system [EMSLAB Group, 1988; Wannamaker et al., this issue] (Figure 1). This profile, called the Lincoln Line because it crosses the northern Oregon coast near the town of Lincoln City, reveals a rich variety of resistivity structures associated with the subduction process. Possible examples include deep structure of the Juan de Fuca spreading regime, the near-offshore accretionary prism, the subduction decollement beneath western Oregon, the High Cascades

\footnotetext{
${ }^{1}$ University of Utah Research Institute, Salt Lake City.

${ }^{2}$ University of Washington, Seatle.

${ }^{3}$ Geological Survey of Canada, Ottawa, Ontario.

${ }^{4}$ AT \& T Bell Labs, Murray Hill, New Jersey.

${ }^{5}$ Scripps Institution of Oceanography, La Jolla, Califomia.

${ }^{6}$ University of Oregon, Eugene.

${ }^{7}$ Geological Survey of Canada, Sydney, British Columbia.
}

Copyright 1989 by the American Geophysical Union.

Paper number 89JB00681.

0148-0227/89/89JB-00681\$05.00 volcanic arc, and the back-arc Deschutes Basin region [Wannamaker et al., this issue]. While a number of aspects of the subsurface resistivity can be deduced straight from inspection of the data, computer simulation of the observations helps to quantify more rigorously the permissible or required structures. In this paper, we derive a two-dimensional resistivity model, with a presumed northsouth strike, by trial-and-error fitting of our MT measurements with a finite element forward modeling algorithm. Constraints on model geometry from independent geological or geophysical investigations have been incorporated where justified.

Our paper is divided into three major sections. First, we explain the approach toward two-dimensional modeling. On land, the transverse magnetic (TM) impedance functions are emphasized because theory and experience show that they are more robust to plausible three-dimensional effects in the region than are the vertical magnetic field or, especially, the transverse electric (TE) impedance. Upper crustal structure on the seafloor appears to be much simpler than on land, however, and both modes of impedance plus the vertical field are fit fairly well. Second, the model cross section is described and its goodness of fit to the data demonstrated. Model uniqueness is investigated by perturbing certain features of the model and assessing the increase in misfit. 


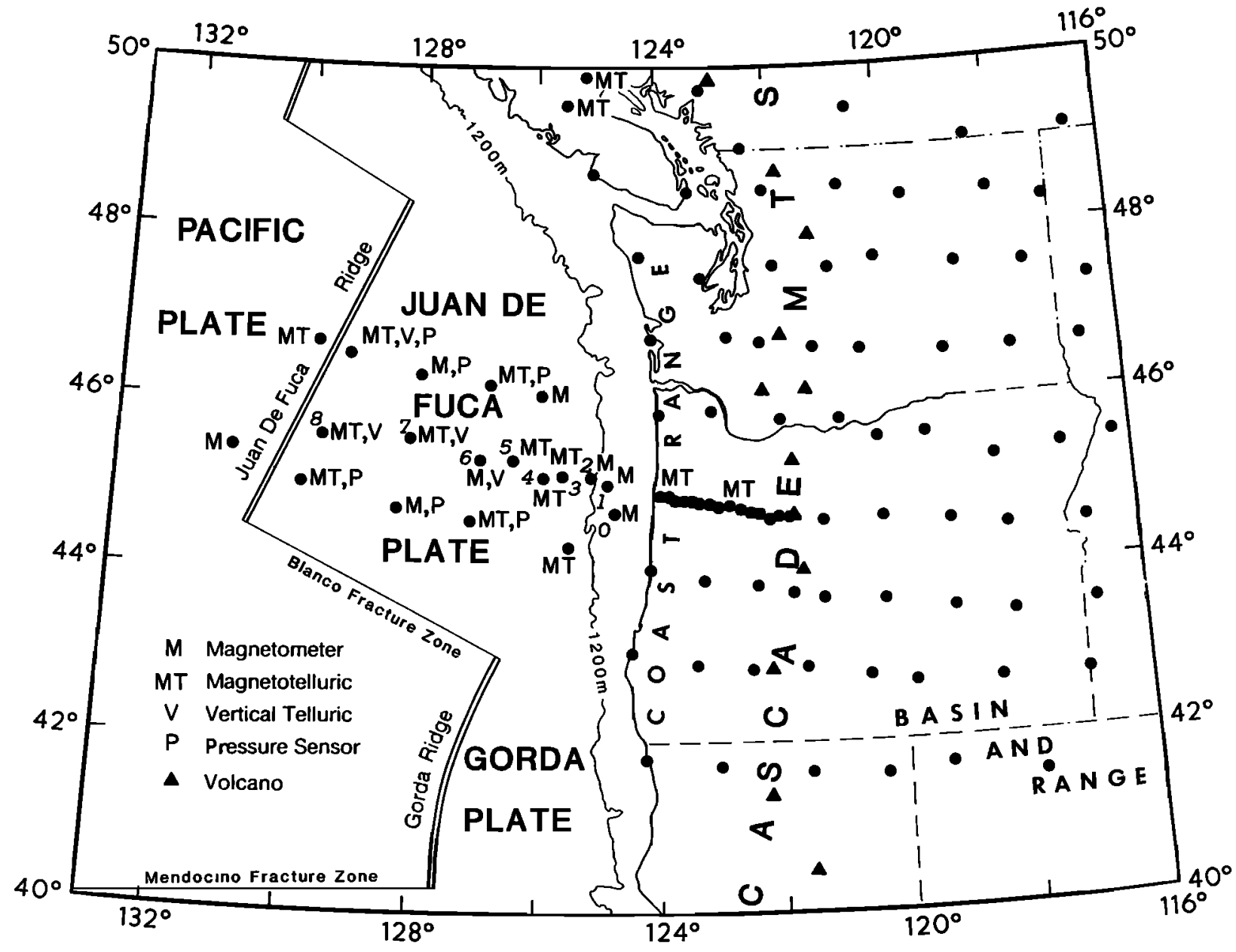

Fig. 1. Instrument location of entire EMSLAB array. On land, the unlabeled dots indicate locations of three-component magnetovariometers. The E-W trending concentration of dots in northwestem Oregon denotes the long-period MT recorders along the land portion of the Lincoln Line. Seafloor array sites are labeled according to instrument type and sites 0-8 are given for the seafloor extension of the Lincoln Line. However, no data were recovered from seafloor sites SF0 and SF6.

This is not a complete method of model appraisal, but it allows us to test our model structure against important competing hypotheses. Finally, our resistivity model offers new insight into the tectonics of the Juan de Fuca system and of the subduction process in general. This is realized within a framework of independent geological and geophysical knowledge, which includes primarily heat flow, seismic velocity, and slab mineralogy.

\section{VALDITY OF TWO-DIMENSIONAL MAGNETOTELLUURIC INTERPRETATION}

We have only one detailed profile of MT observations in the EMSLAB project and so must interpret the observations within primarily a two-dimensional framework. Fortunately, a substantial amount of progress has been achieved in the past several years in understanding the conditions under which two-dimensional interpretation is permissible. In essence, the possibility of two-dimensional approaches depends on the common preferred orientation of tectonism (roughly N-S in the United States and in our study area) and on the observation that some MT functions are much less affected by variations along strike than others.

As reviewed more fully with the data presentation by Wannamaker et al. [this issue], we measure and interpret the complex-valued tensor impedance relating the total electric (E) and magnetic ( $\mathrm{H}$ ) field vectors at the surface of a threedimensional earth, i.e.,

$$
\left[\begin{array}{l}
E_{x} \\
E_{y}
\end{array}\right]=\left[\begin{array}{l}
Z_{x y} Z_{x y} \\
Z_{y x} Z_{y y}
\end{array}\right]\left[\begin{array}{l}
H_{x} \\
H_{y}
\end{array}\right]
$$

A right-handed coordinate system with $z$ positive down is assumed. Over a purely two-dimensional earth with $x$ as the strike direction, the on-diagonal impedance elements $Z_{x x}$ and $Z_{y y}$ are zero while $Z_{x y}$ and $Z_{y x}$ represent the independent transverse electric (TE) and transverse magnetic (TM) modes of polarization. The TE mode is defined as having the electric field (currents) parallel to strike, while the TM mode has the field (currents) across strike. Apparent resistivities (e.g., $\rho_{x y}$ and $\left.\rho_{y x}\right)$ and impedance phases $\left(\phi_{x y}\right.$ 
and $\left.\phi_{y x}\right)$ are formed from the complex elements for subsequent interpretation. Similarly, the relationship

$$
\left[H_{2}\right]=\left[\begin{array}{ll}
M_{2 x} & M_{2 y}
\end{array}\right]\left[\begin{array}{l}
H_{x} \\
H_{y}
\end{array}\right]
$$

is defined for the vertical magnetic field. Over a twodimensional earth, $M_{2 x}$ is zero and $M_{z y}$ arises from the TE mode of polarization.

Our recommendation for two-dimensional interpretation is to derive a resistivity cross section emphasizing the TM mode data since the two-dimensional assumption for this mode is much more robust. For example, it has been shown that two-dimensional modeling of synthetic TM mode data across simple, elongate three-dimensional structures yields accurate resistivity cross-sections [Wannamaker et al., 1984]. The profile in fact does not need to be close to the center of the three-dimensional body for this to occur. Furthermore, a two-dimensional TM interpretation of $\rho_{y x}$ and $\phi_{y x}$ is possible even when upper crustal inhomogeneity is more complex. In this case, such an interpretation yields a cross section which may be somewhat incorrect in its surficial features but represents accurately the regional resistivity structure of interest provided the regional structure itself is not arbitrarily three-dimensional [Jones, 1983; Bostick, 1986; Kariya, 1986; Wannamaker, 1989, in press]. For two-dimensional modeling, the MT functions should be defined using a fixed coordinate system approximating the strike direction to overcome unwanted effects of near-surface structure, specifically on the impedance phase [Wannamaker et al., 1984].

The Lincoln Line profile was designed to meet the foregoing criteria for three-dimensional modeling emphasizing the TM mode. Observed geological and physiographic trends in the region are oriented predominantly N-S [Baldwin, 1981]. This is implied also by most of the gravity data [Riddihough and Seeman, 1982]. Some departure from an assumed N-S geoelectric strike in the upper crust is indicated along the east side of the Willamette Basin and the west side of the High Cascades graben. However, most resistivity variations, and especially the deeper ones presumably associated with subduction, appear to trend mainly N-S beneath our data profile according to their effect on $M_{z x}$ and $M_{z y}$ [Wannamaker et al., this issue]. Furthermore, the preliminary mini-EMSLAB soundings taken about $50 \mathrm{~km}$ south of the Lincoln Line [Young et al., 1988] also exhibit the major features of the present study, in particular the subtle peak in $\phi_{y x}$ below the Coast Range and its substantial increase to the east. Consequently, a fixed N-S strike direction is defined for two-dimensional modeling of the Lincoln Line data.

In contrast, three-dimensional effects can be quite severe for the TE mode and reliable interpretations of this data require care. Specifically, any structure introduced to model $\rho_{x y}$ and $\phi_{x y}$ should also improve the fit to the vertical magnetic field. This is because three-dimensional effects on the TE impedance tend to be of an opposite sense than on $M_{z y}$. For example, over simple three-dimensional conductive inhomogeneities, finite strike length typically depresses the electric field, and thus the impedance, relative to the twodimensional TE response [Wannamaker et al., 1984]. This downward bias persists to arbitrarily long periods, tending to make the three-dimensional impedance appear more anomalous than the two-dimensional one. In attempting to replicate the three-dimensional effect in $\rho_{x y}$ and $\phi_{x y}$ using a two-dimensional TE routine, one would thus need to place additional (i.e., false) low-resistivity material beneath the true conductor. However, $M_{z y}$ appears less anomalous over a finite length conductor than over a fully two-dimensional one. This occurs because the depression of electric field (and thus current) within the three-dimensional body reduces $\mathrm{H}_{2}$ in its vicinity relative to the two-dimensional case. Finally, modeling of the TE results should not compromise the TM mode fit. If the foregoing conditions cannot be met, then three-dimensional effects are probably at hand and require appropriate three-dimensional modeling.

\section{MODEL RESISTIVITY CROSS-SECTION}

Our preferred two-dimensional resistivity model for the Lincoln Line is presented in this section. It has been obtained by trial-and-error fitting of the data using the finite element forward algorithm described by Wannamaker et al. [1986, 1987]. Triangular element shapes allow simulation of polygonal resistivity media, including a precise representation of the ocean bathymetry. Consequently, the oceanic MT responses of our model could be calculated at the bottom of the seawater where the data were measured. For the detailed MT profile on land (Figure 2), the TM mode impedance functions $\rho_{y x}$ and $\phi_{y x}$ were given greatest weight through most of the fitting process. The vertical magnetic field, however, was valuable in understanding several areas of the subsurface structure, especially those under the continental shelf and slope and deep under the High Cascades. The TE quantities $\rho_{x y}$ and $\phi_{x y}$ on land have been useful in revealing important off-line resistivity variations. In contrast, a single two-dimensional model explains both the TE and TM mode impedance functions plus the vertical magnetic field on the seafloor at least for periods up to $10^{4} \mathrm{~s}$.

Several constraints on model geometry were incorporated. First, the bathymetric contours of the Juan de Fuca plate relief map of the Pacific Geoscience Center [Geological Survey of Canada] were used to specify the depth of the seawater, which was given a resistivity of $0.3 \mathrm{ohm} \mathrm{m}$ [Filloux, 1987]. Second, thicknesses of conductive sediments over resistive marine basalts in the near-offshore Newport Basin and the abyssal Cascadia Basin were simplified from the geologic section of Snavely [1987]. The base of conductive sediments of the Willamette Basin was modeled as a sharp interface with resistive rocks below in keeping with deposition over igneous or metamorphic basement. The resistivity model in the High Cascades graben and vicinity was patterned after the volcanic stratigraphy and structure presented by Priest et al. $[1983,1987]$. At $400 \mathrm{~km}$ depth, a very low resistivity $(0.3$ ohm $\mathrm{m}$ ) half-space was imposed to represent the global decrease in resistivity near there [Banks, 1972; Roberts, 1986].

Generally, our model was constructed from the near-surface (short periods) downward. Deep structure was included only when the data could not be explained by shallow structure. The abrupt nature of the resistivity boundaries in the model, which are an implicit constraint of the finite element 


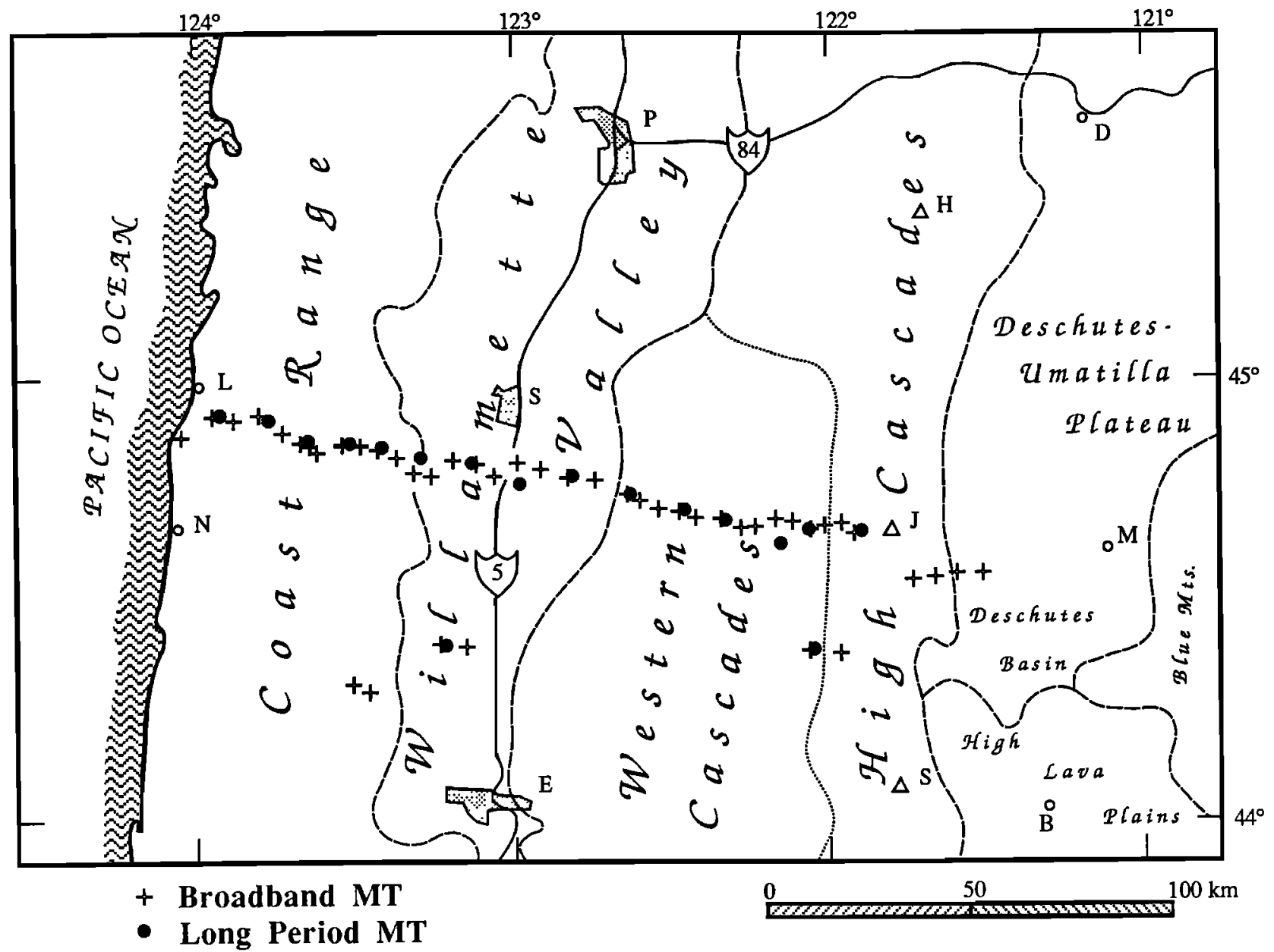

Fig. 2. Broadband and long-period magnetotelluric soundings along the landward portion of the Lincoln Line and also along the mini-EMSLAB test traverse father south [Young et al., 1988]. Urban areas include Portland (P), Salem (S), Eugene (E), Newport (N), Lincoln City (L), Bend (B), Madras (M), and The Dalles (D). Cascades volcanoes are labeled as triangles: Mount Hood $(\mathrm{H})$, Mount Jefferson $(J)$, and South Sister (S).

algorithm, should not be taken literally. Because our data are imprecise and finitely sampled, and because the propagation of electromagnetic fields in the Earth is diffusive, the data can only resolve smooth resistivity variations in the subsurface. We presume that the media in our finite element model approximately represent local averages of conductivity (inverse of resistivity).

\section{Model Resistivity Cross Section}

The two-dimensional finite element resistivity model is presented in Figure 3 and Plate 1 in slightly simplified form. (Plate 1 can be found in the separate color section in this issue.) Specifically, the resistivity values have been grouped into ranges of one-half decade in order to emphasize the major structural members of the model. Minor variations within each group occur predominantly in the upper $2 \mathrm{~km}$ of the model and simulate local, short-period anomalies. Note the vertical scale changes at 5 and $150 \mathrm{~km}$.

The landward portion of the Lincoln Line model (Figure 3) resembles that of EMSLAB Group [1988] but is refined somewhat. Marine basaltic rocks of the Siletz River formation [Snavely, 1987] outcropping in the Coast Range possess resistivities of the order of $100 \mathrm{ohm} m$ or a bit less. Below them at a depth of about $2 \mathrm{~km}$ lies a low resistivity unit which is essentially horizontal under most of this area. Conductive marine sediments and alluvium of the Willamette Basin deepen steadily to the east and reach a thickness of $3.75 \mathrm{~km}$ nominally by $y=75 \mathrm{~km}$ (distance east of the coast). Farther inland, the thickness decreases to only about $2 \mathrm{~km}$ by $y=100 \mathrm{~km}$, near the town of Stayton, beyond which there is a second, lesser depth maximum. Low resistivity extends about $20 \mathrm{~km}$ east of the Willamette Valley-Western Cascades physiographic boundary.

Farther east, the Western Cascades block contains high resistivities extending close to the surface (Figure 3 ). Around $y=145 \mathrm{~km}$, a new low-resistivity layer appears at a depth of only $500 \mathrm{~m}$ or so below mainly basaltic rocks of the High Cascades extrusive platform [Priest et al., 1983]. The layer deepens only slightly eastward but, somewhere below the present High Cascades axis (about $y=170 \mathrm{~km}$ ), undergoes an abrupt fivefold increase in conductance (conductivitythickness product) and deepens to about $600-800 \mathrm{~m}$ beneath extensive Pliocene basalt flows overlying the Deschutes Basin. All the conductive upper crustal units just described reside on a basement and middle crust which is resistive 


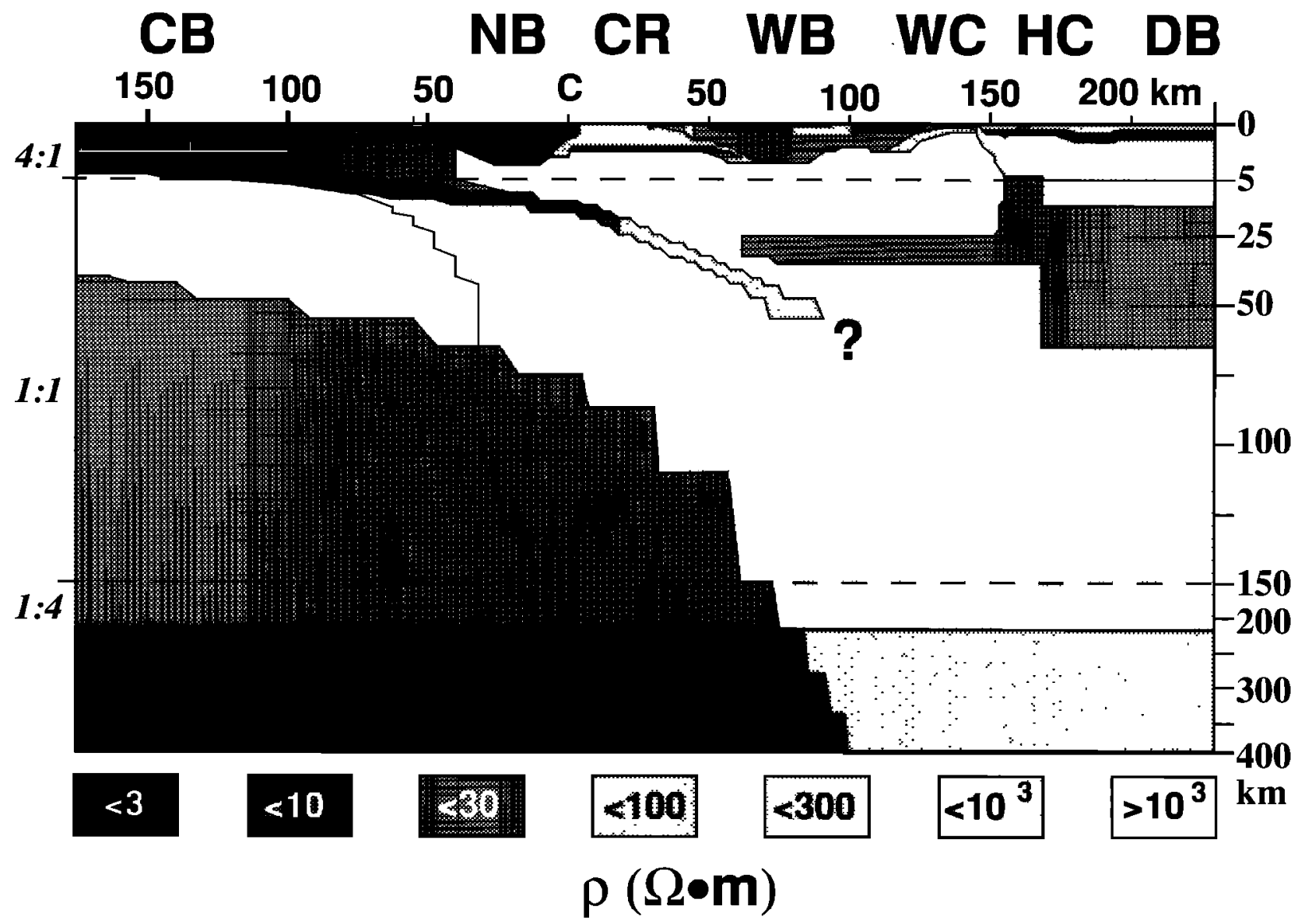

Fig. 3. East-west resistivity cross section derived from forward modeling of MT data along the Lincoln Line. Section preserves details of the finite element mesh geometry but resistivities have been grouped in half-decade intervals for grayscale display. Seafloor portion of the model is shown only to $175 \mathrm{~km}$ offshore, beyond which variations are minor. Note changes in vertical exaggeration, labelled on the left, at 5 and $150 \mathrm{~km}$ depth. Important physiographic regions crossed include the Cascadia Basin (CB), Newport Basin (NB), Coast Range (CR), Willamette Basin (WB), Western Cascades (WC), High Cascades (HC), and the Deschutes Basin (DB). A color version of this cross section appears as Plate 1 in the separate color section of this issue.

throughout (hundreds of ohm-m). It is difficult to resolve variations within the basement, but the highest resistivities appear to exist under the Western Cascades.

Perhaps the best determined element of the deeper structure is the subhorizontal conducting layer below $25 \mathrm{~km}$ extending east from about $y=60 \mathrm{~km}$. The conductance of this layer is $600 \mathrm{~S}$, and it is responsible for the strong ridge in the TM phase $\phi_{y x}$ at 30-100 $\mathrm{s}$ and the distinct minimum in $\rho_{y x}$ described in the data paper [Wannamaker et al., this issue]. The bottom of the conductor is somewhat shallower than in the preliminary model presented by EMSLAB Group [1988] and fits the TM phase better below the Western Cascades and eastern Willamette Basin at periods from $300-3000 \mathrm{~s}$. This conductor appears to be resolved as well by the detailed geomagnetic measurements of Hermance et al. [1989, in press] in a profile some $30 \mathrm{~km}$ to the south of the Lincoln Line. Just west of the present High Cascades chain, a relatively narrow conductive axis extends up from the subhorizontal conductor to about $5 \mathrm{~km}$ from the surface.

East of the High Cascades beneath the Deschutes Basin, the subhorizontal deep conductor is shown thicker by a factor of about 6. Its top is somewhat shallower, and its bottom is substantially deeper. However, a precise determination of its depth extent is made difficult by a strong regional threedimensional effect east of the High Cascades, as described later.

Another important member of the deeper structure is a lowresistivity layer beneath the Coast Range. This layer dips eastward about $20^{\circ}$ from a depth near $12 \mathrm{~km}$ under the coastline to $45 \mathrm{~km}$ under the west-central Willamette Basin. Our data suggests the layer is thin relative to its depth such that only its conductance can be resolved. The conductance of this dipping unit decreases eastward from a maximum near $1000 \mathrm{~S}$ under the coast to less than $100 \mathrm{~S}$ by $y=60 \mathrm{~km}$. Its exact geometric relation to the subhorizontal conductor discussed previously cannot be determined from our data. In contrast to the model of EMSLAB Group [1988], the two conductive layers are not connected near $y=60 \mathrm{~km}$, but instead a small resistive gap is shown which negligibly affects the response. The data neither require nor forbid an extension of the dipping, low-conductance layer under the subhorizontal conductor above it. 
The ocean bottom portion of the finite element model is drawn only as far as $y=-175 \mathrm{~km}$ in Figure 3 and Plate 1. Beyond this, the model remains essentially the same apart from a gradual decrease in the conductance of the lowresistivity sedimentary layer of the abyssal Cascadia Basin from values around $2500 \mathrm{~S}$ beneath site SF3 to essentially zero at SF8 near the ridge. The resistivities of the sediments of this basin and of the near-shore Newport Basin are very low, in the range of 1-2 ohm $\mathrm{m}$. However, the resistivity of the Miocene and older melange and broken formation [Snavely, 1987], which protrude to shallow depths beneath the geomagnetic variation sites SF1 and SF2, is much higher with a value of nearly $30 \mathrm{ohm} \mathrm{m}$ in our model. Extending down the trench and connecting to the dipping conductor beneath the Coast Range is a strip of low resistivity whose conductance, however, is lower than that of the Cascadia Basin sediments nearby. The continuity of this strip is tenuous and resolved best by the westernmost land MT stations. Shallow water MT measurements would be necessary to resolve trench structure with more confidence. These are logistically very difficult because the continental shelf is swept continuously by fishing nets.

Below the conductive seafloor sedimentary layer resides a resistive (3000 ohm $\mathrm{m}$ ) lithosphere a few tens of $\mathrm{km}$ thick (Figure 3). This unit is resolved best by the western two MT sites where the seafloor sediments are relatively thin and do not screen the response of the resistive layer below. At depths near $35 \mathrm{~km}$, we see a dramatic fall in resistivity to around $20 \mathrm{ohm} \mathrm{m}$ from $3000 \mathrm{ohm} \mathrm{m}$. This conductive region is responsible for the steep drop in apparent resistivities and the high impedance phases at the shortest periods at SF7 and SF8. In the model, the resistivity of this mantle region is essentially constant to a nominal depth of $215 \mathrm{~km}$. Models of geomagnetic variations by Law and Greenhouse [1981] and DeLaurier et al. [1983] suggest that resistivity increases again below about $100 \mathrm{~km}$, but the deeper reaches of these models are relatively poorly resolved [Oldenburg et al., 1984]. At depths beyond $215 \mathrm{~km}$ in the oceanic mantle, even lower resistivities (about $1 \mathrm{ohm} \mathrm{m}$ ) are shown. However, the resistivities at this depth and beyond are difficult to resolve. This difficulty stems from an inconsistency between the apparent resistivity and impedance phase of both modes at periods of $10^{4} \mathrm{~s}$ and more, as discussed later with the calculated response curves. The eastward extent of the oceanic mantle conductor is not well defined but extending it east of the coast helps simulate the abrupt falloff in $M_{z y}$ at periods below about $500 \mathrm{~s}$. The conductivity below $215 \mathrm{~km}$ in fact could be drawn across the entire section because the land data considered extends only to $10,000 \mathrm{~s}$ period.

\section{Computed Response Pseudosections}

Next we show the calculated MT responses of the model for comparison with the observations in Wannamaker et al. [this issue]. First will be the TM mode quantities $\rho_{y x}$ and $\phi_{y x}$ since they have been emphasized in the modeling. As seen in Figure 4 and Plate 2, the agreement on land of the calculations with observations is very good in both apparent resistivity and impedance phase. The fit of the model to the observed $\rho_{y x}$ and $\phi_{y x}$ on the seafloor is shown in Figure 5 and Plate 3 and is similarly good with one exception. (Plates 2 and 3 can be found in the separate color section of this issue.) At the very long periods, greater than $10^{4} \mathrm{~s}$, computed $\rho_{y x}$ is

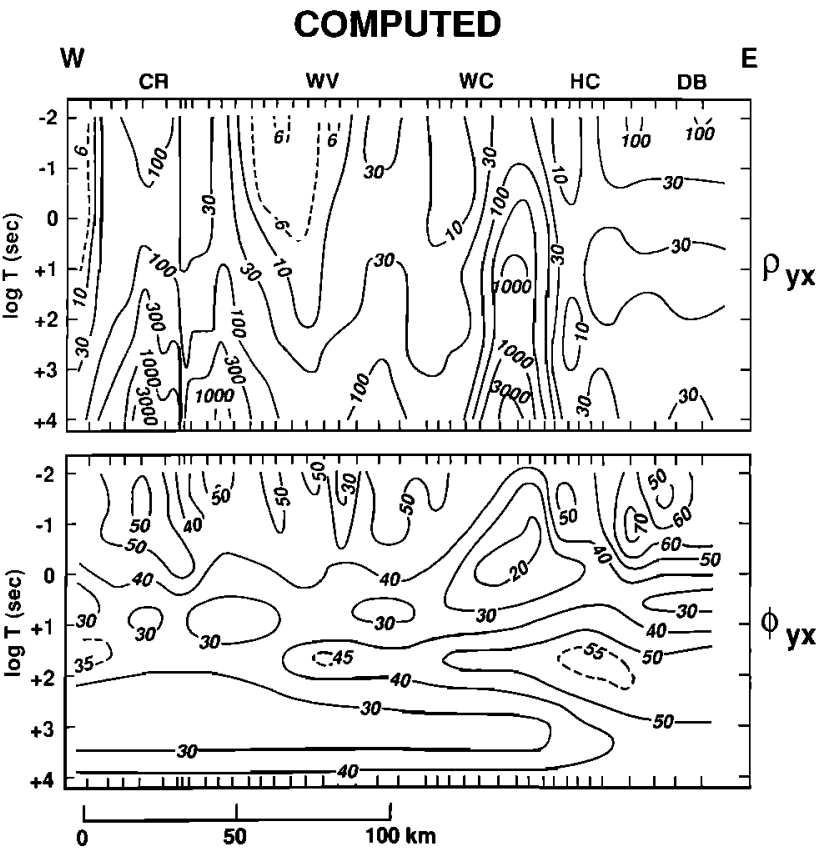

Fig. 4. Pseudosections of calculated transverse magnetic apparent resistivity $\rho_{y x}$ and impedance phase $\phi_{y x}$ along the landward portion of the Lincoln Line. Contour values of $\rho_{y x}$ are in ohm $\mathrm{m}$ and of $\phi_{y x}$ are in degrees. These and subsequent pseudosections should be compared to observed pseudosections presented by Wannamaker et al. [this issue] to assess goodness of fit. Color versions of these pseudosections appear in Plate 2 in the separate color section of this issue.

\section{COMPUTED}

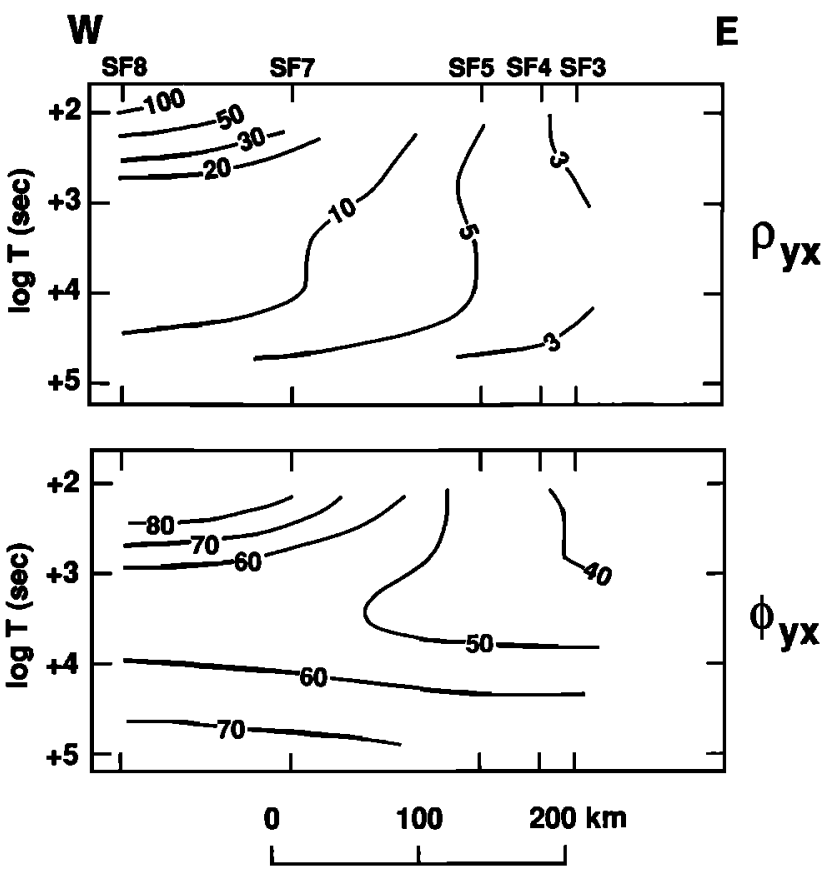

Fig. 5. Pseudosections of calculated transverse magnetic apparent resistivity $\rho_{y x}$ and impedance phase $\phi_{y x}$ for the five MT soundings on the ocean bottom segment of the Lincoln Line. Contours of apparent resistivity are in ohm $\mathrm{m}$ and of impedance phase in degrees. Color versions of these pseudosections appear in Plate 3 in the separate color section of this issue. 
somewhat smaller than observed although the fit to $\phi_{y x}$ is good. This discrepancy is even worse for the TE quantities described subsequently and reflects an inconsistency in the very long-period seafloor data to which we will return.

The calculated TE pseudosections $\left(\rho_{x y}\right.$ and $\left.\phi_{x y}\right)$ for the land segment of the Lincoln Line appear in Figure 6 and Plate 4. (Plate 4 can be found in the separate color section of this issue.) While they resemble the data of Wannamaker et al. [this issue] to some extent, the assumption of a twodimensional structure for the TE mode fails seriously in several areas of the response. Due to the variety of threedimensional effects interpreted to exist in the TE data on land, these data have not been utilized in determining the structure of our model. Most obviously, the two-dimensional TE model calculations show a very smooth lateral variation in $\rho_{x y}$ at periods longer than about $10 \mathrm{~s}$. In contrast, the data pseudosections retain a strong vertical orientation to the apparent resistivity contours. This fundamental difference results from numerous finite strike length effects in the measured TE data over upper crustal conductive structures under our profile.

There are at least three other discrepancies between calculated and measured TE data that are due to threedimensional effects. First, no two-dimensional geometry can reproduce the very long-period anomalies in $\phi_{x y}$, and the slope of $\rho_{x y}$ versus $T$, of narrow lateral extent around $y=30$, 40 and $135 \mathrm{~km}$ [Wannamaker et al., this issue]. We must appeal to some three-dimensional connection or coupling between upper crustal structures local to the measurement sites and large-scale bodies off-line to our profile for an explanation. Next, approaching $10^{4} \mathrm{~s}$, calculated $\phi_{x y}$ on average over the whole land segment becomes higher than observed, while the fall in $\rho_{x y}$ vs. period becomes too steep.
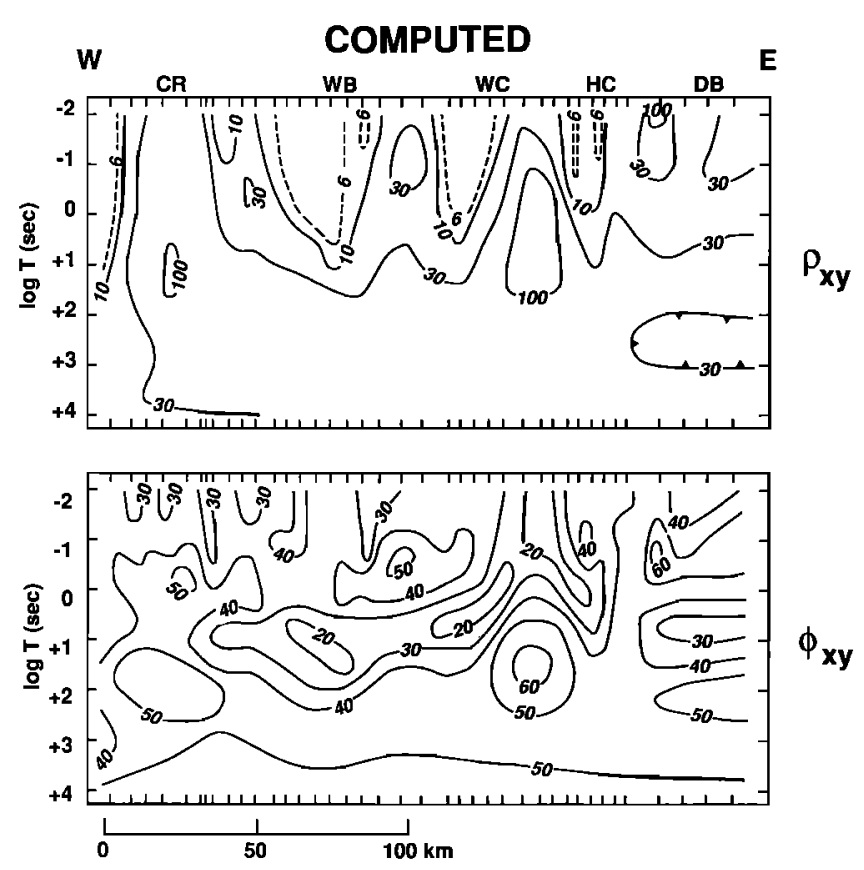

Fig. 6. Pseudosections of calculated transverse electric apparent resistivity $\rho_{x y}$ and impedance phase $\phi_{x y}$ along the landward portion of the Lincoln Line. Color versions of these pseudosections appear in Plate 4 in the separate color section of this issue.
The high calculated $\phi_{x y}$ results from the very low resistivities deep in the oceanic mantle, which must not be affecting the land data in a two-dimensional manner for the TE mode. Finally, the three-dimensional nature of deep resistivity structure below the Deschutes Basin affects $\rho_{x y}$ and $\phi_{x y}$ strongly here at long periods. The calculated response of the preferred model in Figure 6, is far too low for $\rho_{x y}$ and too high for $\phi_{x y}$ at periods longer than about $10 \mathrm{~s}$. An E-W boundary a few tens of kilometers south of our profile, with deep conductive material on its farther side, explains the occurrence [cf. Wannamaker et al., 1984]. Such a geometry has been indicated by Gough et al. [this issue] from their geomagnetic array measurements. They have named the resistive northern region the Blue Mountains Resistive Block. The conductive Basin and Range province is to the south.

This east-west boundary provides an example, on the Lincoln Line, where a purely two-dimensional TM mode analysis may be inaccurate due to "sideswipe" by a nearby, off-line structure of regional extent. The TM data alone suggest low resistivity to depths of at least $100 \mathrm{~km}$ here while the vertical magnetic field, which is measured to $10^{4} \mathrm{~s}$, implies that conductor depth extent is limited to only $65 \mathrm{~km}$, as shown in Figure 3. The true upper mantle structure below the Deschutes Basin will not be resolved more precisely without three-dimensional simulations and probably further N-S MT profiling in this region.

On the seafloor, as stated earlier, the preferred twodimensional model fits both TM and TE mode impedance responses almost equally well, at least down to $10^{4} \mathrm{~s}$ (Figure 7 and Plate 5). (Plate 5 can be found in the separate color

\section{COMPUTED}
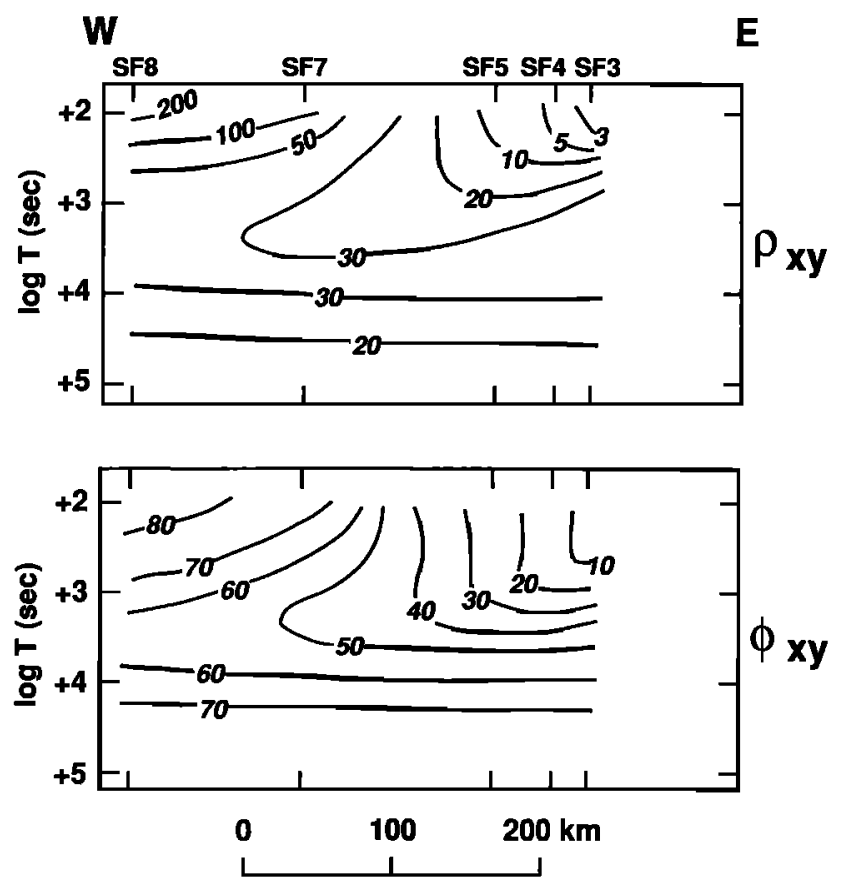

Fig. 7. Pseudosections of calculated transverse electric apparent resistivity $\rho_{x y}$ and impedance phase $\phi_{x y}$ along the seafloor portion of the Lincoln Line. Color versions of these pseudosections appear in Plate 5 in the separate color section of this issue. 
section of this issue.) One notable example of the twodimensional nature of the TE mode here at moderate periods is the fact that $\rho_{x y}$ below about $3000 \mathrm{~s}$ appears laterally uniform across the whole seafloor segment of the Lincoln Line. The inconsistency between the observed apparent resistivity and phase at periods greater than $10^{4} \mathrm{~s}$, noted earlier for the TM mode, is even more obvious in the TE. Specifically, we can fit $\phi_{x y}$ with the model of Figure 3 but not $\rho_{x y}$. This difficulty is discussed further in the upcoming sensitivity tests.

The vertical magnetic field function $M_{2 y}$ particularly on land has been of greater use in the interpretation of the Lincoln Line than have the TE impedance quantities $\rho_{x y}$ and $\phi_{x y}$. The areas of greatest value include the resistivities of the sedimentary sections offshore and the conductive axis associated with the High Cascades volcanic arc. The calculated response of $M_{x y}$ appears in Figure 8 and Plate 6 and its agreement with the observations of Wannamaker et al. [this issue] is good overall. (Plate 6 can be found in the separate color section of this issue.) One minor area of disagreement occurs near the westernmost edge of the Willamette Basin sediments $(y \simeq 30 \mathrm{~km})$. The measured response here is weaker probably because the sediments are areally very patchy, i.e., have poor N-S continuity. The computed pseudosections of $M_{z y}$ for the seafloor stations appear in Figure 9 and Plate 7 and show good agreement with the data of Wannamaker et al. [this issue] as well. (Plate 7 can be found in the separate color section of this issue.) That the vertical magnetic field is so much more consistent with the TM mode impedance functions than with the TE mode impedance implies a greater continuity along strike of the current-density variations, which determine $H_{z}$, relative to the electric field variations, which affect the TE impedance.
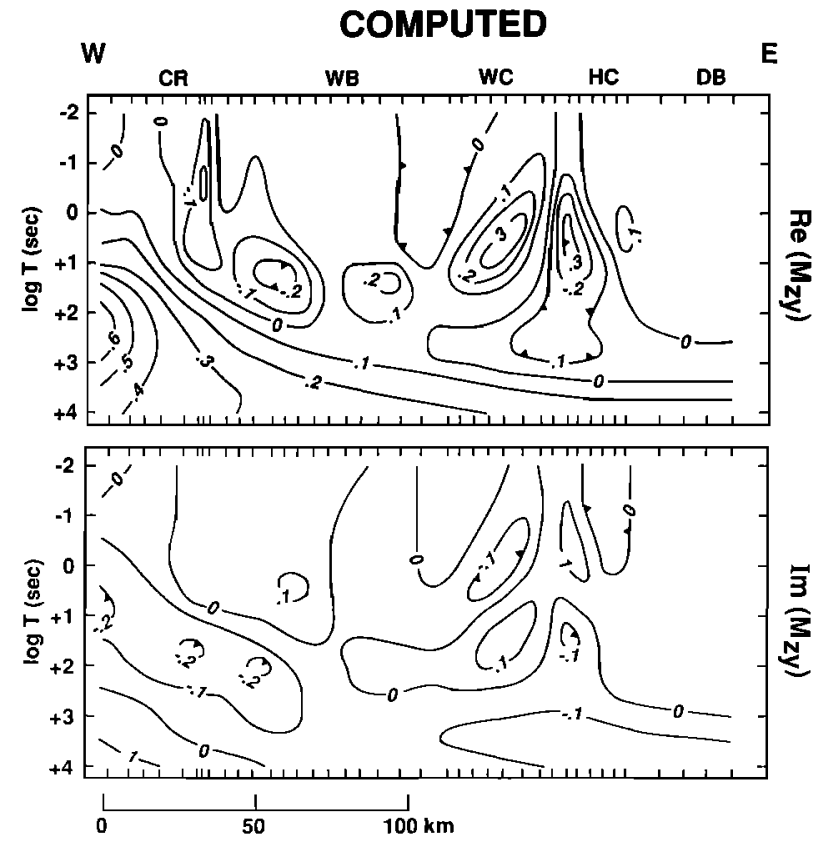

Fig. 8. Pseudosections of calculated vertical magnetic field transfer function $M_{z y}$ along the landward portion of the Lincoln Line. Color versions of these pseudosections appear in Plate 6 in the separate color section of this issue.
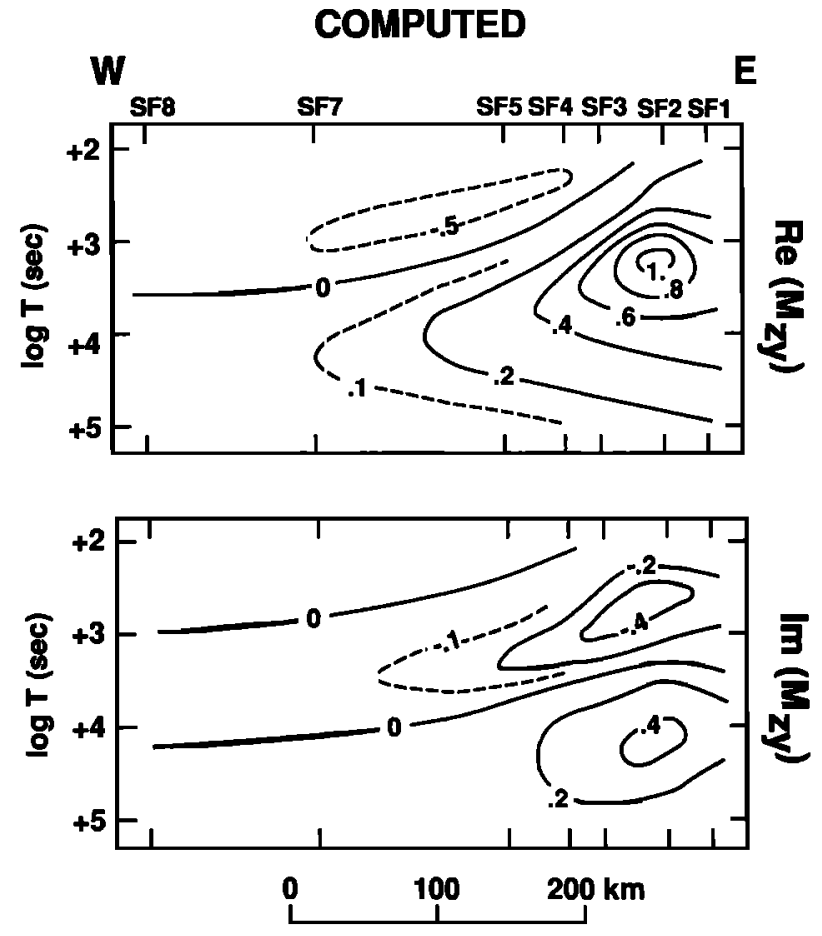

Fig. 9. Pseudosections of calculated vertical magnetic field transfer function $M_{2 y}$ for the seafloor portion of the Lincoln Line. Color versions of these pseudosections appear in Plate 7 in the separate color section of this issue.

\section{Model-Response Sensitivity Tests}

Any interpretation of incomplete, inaccurate geophysical data involves nonuniqueness [Parker, 1977]. We have presented a model that fits the data very well. Other models undoubtedly exist. One approach to a nonunique problem is to look for models with minimum structure required to explain the data. We have undertaken this in an informal way by adding deep structure only when the data could not be explained by shallow structure. Jiracek et al. [this issue] implement such an approach in a formal way by minimizing a mathematical measure of structure subject to a certain level of data misfit. Another approach is to perturb structural elements and examine the effect on the data. This is not a complete method of model appraisal because one limits the search for alternate models to those that are fairly close to the starting model. However, it allows one to directly test a model against important competing hypotheses [Parker, 1977].

We will follow the latter approach. Our initial tests concern the subhorizontal deep conductor below the central Willamette Basin to the High Cascades. Figure 10 displays the observed TM and TE quantities for a site $123 \mathrm{~km}$ inland from the coast. The goodness of fit of the preferred model of Figure 3 and Plate 1 is apparent (solid curves of $\rho_{y x}$ and $\phi_{y x}$ ). Note that the broadband and long-period sites are not exactly coincident in geographic location so that the long-period apparent resistivities have a small static shift relative to the broadband. It is only important in this case that the model response be parallel to the long-period data in the log-log plot and that the phase be fit. 

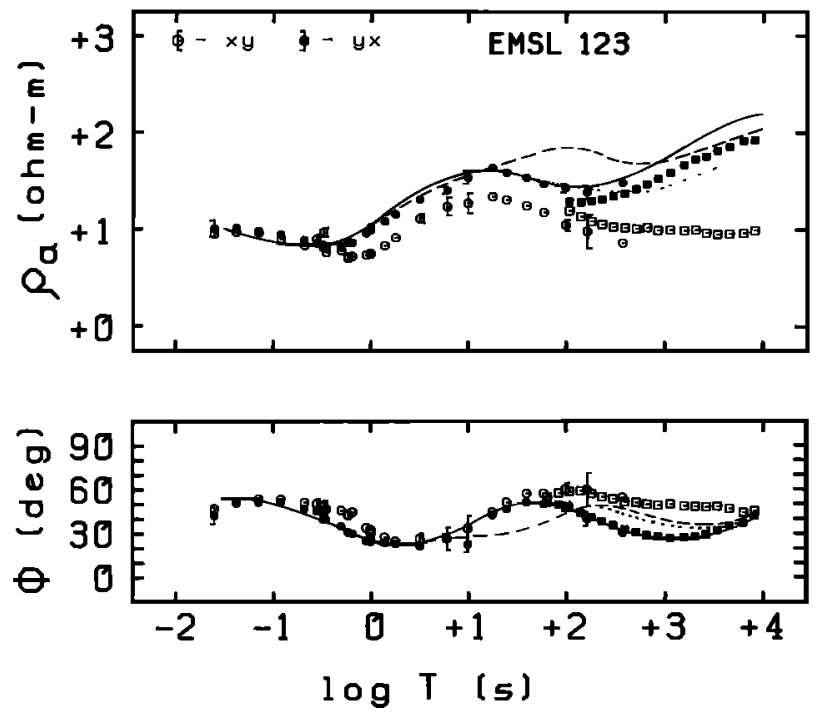

Fig. 10. Broadband and long-period MT data collected by the University of Oregon and the Geological Survey of Canada (GSC) about $123 \mathrm{~km}$ inland on the Lincoln Line. Error bars are one standard deviation plotted where larger than data symbol. The solid curve is the calculated TM mode response for the preferred model of Figure 3. A test case rejected for its misfit is that of removing the strong, subhorizontal conductor east from the central Willamette Basin to the High Cascades and instead extending the Coast Range conductor downdip to $85 \mathrm{~km}$ depth beneath the High Cascades (dashed curves). A second alternative rejected has high conductivity from $25 \mathrm{~km}$ depth through to the downdip extension of the Coast Range conductor (dotted curve).

As a first test model, the subhorizontal conductor is removed and the dipping conductor under the Coast Range simply extended downdip to $85 \mathrm{~km}$ depth below the High Cascades (Figure 10). The conductance of the layer is increased downdip also to preserve the amplitude of the peak in $\phi_{y x}$; for example, the layer conductance at $65 \mathrm{~km}$ depth for this test is about $10^{4} \mathrm{~S}$. One sees from the dashed curves of $\rho_{y x}$ and $\phi_{y x}$ that such an alternative is untenable since the period range of both the peak in $\phi_{y x}$ and the minimum in $\rho_{y x}$ is clearly too low. As a second test model, we add lowresistivity material from the top of the subhorizontal conductor at $25 \mathrm{~km}$ depth all the way down to the extended dipping conductor just considered. The response of this structure (dotted curves) also is inconsistent with the observations as it extends the phase peak to periods which are too long and reduces both the amplitude and slope of the apparent resistivity below what were measured. However, the observations do allow an extension of the dipping Coast Range conductor below the subhorizontal layer at $25 \mathrm{~km}$ depth as long as the conductance of the former is limited, e.g., to no more than about $1000 \mathrm{~S}$ at $65 \mathrm{~km}$ depth.

The next tests, illustrated in Figure 11, concern the pronounced, uplifted conductive axis beneath the High Cascades and the depth to the bottom of the deep subhorizontal conductor under the Deschutes Basin. Removing the uplifted axis violates $\operatorname{Re}\left(M_{2 y}\right)$ in the period range from 100 to $1000 \mathrm{~s}$ around $y=147 \mathrm{~km}$ (dashed curves). It also destroys the closure of the negative contours in the pseudosection of $M_{2 y}$ in the same period range (Figure 8 and Plate 6). That a single two-dimensional structure explains
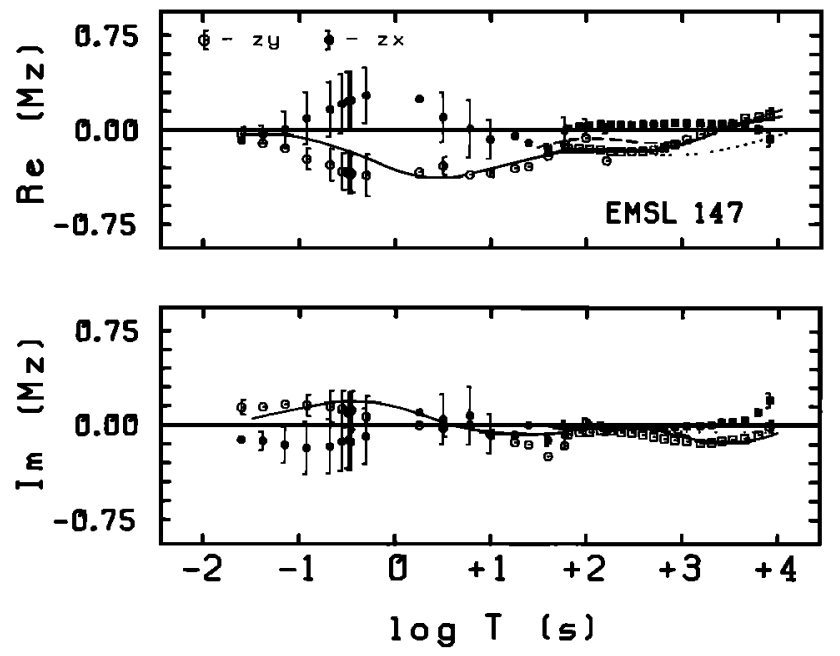

Fig. 11. Real and imaginary observed response curves for elements $M_{2 x}$ and $M_{z y}$ measured by University of Oregon and GSC about $147 \mathrm{~km}$ inland on the Lincoln Line. Computed responses include that of the model of Figure 3 (solid curves), that with the midcrustal conductive axis removed (dashes), and that with the mantle conductor below the Deschutes Basin increased to infinite depths (dots).

both the vertical field and TM response implies that the conductive axis has substantial N-S continuity. To the east, the TM response requires the subhorizontal conductor extending to at least $100 \mathrm{~km}$ depth and essentially can detect no bottom. However, an infinite depth extent disagrees with observed $M_{2 y}$ at periods longer than about $1000 \mathrm{~s}$ (dotted curves). We suspect that the TM response is sensing higher conductivity of the Basin and Range to the south and that a bottom of nominally $65 \mathrm{~km}$ consistent with $M_{z y}$ is more likely. Again, additional N-S profiling and threedimensional modeling are the proper means of resolving the deep structure here.

The sensitivity of the MT response to the geometry of the dipping thin conductor below the Coast Range is assessed in Figure 12. Here we present the TM mode impedance phase values measured in the period range $3-300 \mathrm{~s}$ at sites 1,48 , and $71 \mathrm{~km}$ inland from the coast. In the top panel, the phases from all three sites are superimposed to show that the peaks in $\phi_{y x}$ are distinct both in amplitude and period range within the scatter of the data points. In the lower panels, the phases are plotted as one standard deviation error bars centered on the measured values to demonstrate the good data quality. The solid curves labeled "1", "a", and "A" indicate the goodness of fit of our model to the measured $\phi_{y x}$. The fit to $\rho_{y x}$ at these three sites is equally good, as exemplified for the site at 48 $\mathrm{km}$ in the EMSLAB Group [1988], and as can be deduced from the color pseudosections. Curves of dashes and dots in Figure 12 are responses of alternate models discussed next.

That the Coast Range conductive layer dips inland appears to be resolved by our MT measurements independently and is not imposed from external tectonic considerations. In the first test, we make this layer flat and extend it westward to infinity with a constant depth to top of $30 \mathrm{~km}$. The calculated $\phi_{y x}$ response at $48 \mathrm{~km}$ (not shown) is essentially unchanged. However, at $1 \mathrm{~km}$ (dashed curve "2" in Figure 12) the phase anomaly has significantly lower amplitude and peaks at 


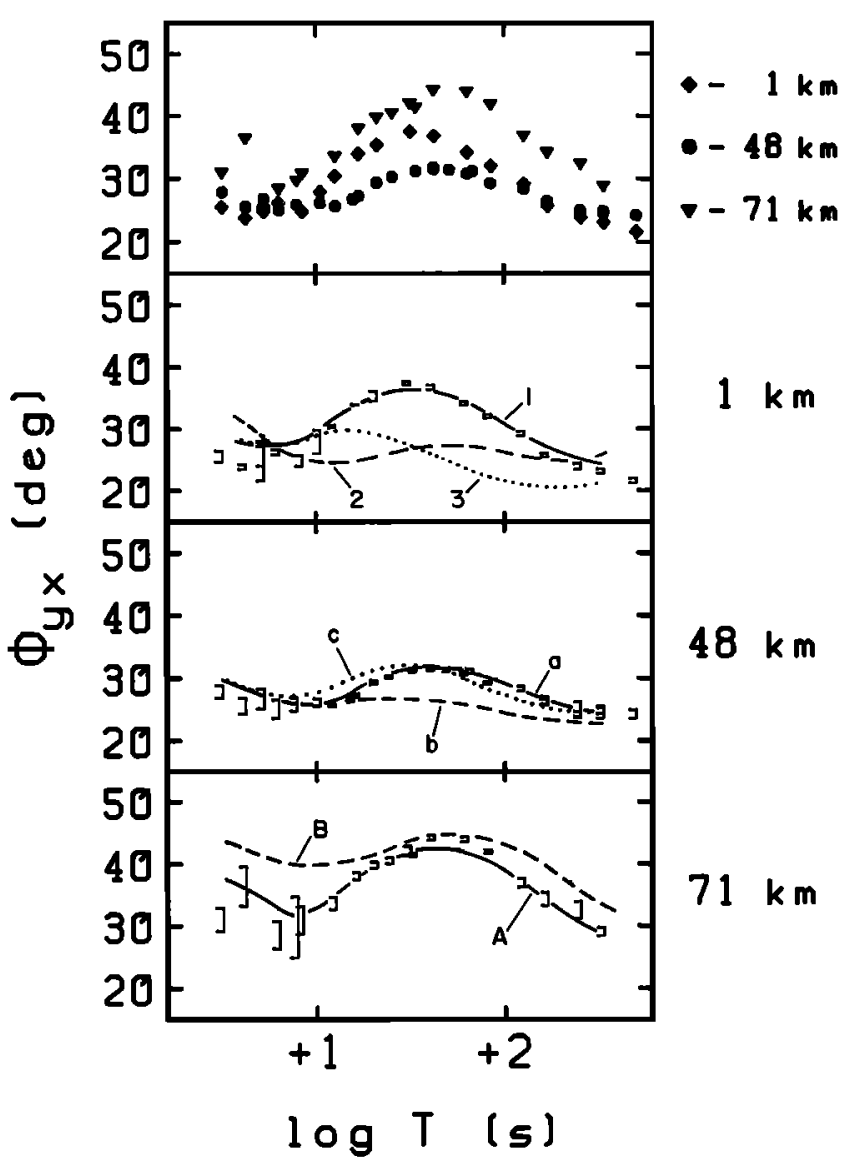

Fig. 12. Transverse magnetic impedance phase $\phi_{x y}$ in the period range 3-300 s approximately at sites which are 1,48 , and $71 \mathrm{~km}$ inland from the coast. Phases in the lower panels are represented by one standard deviation error bars centered on the estimated values. Solid curves are the response of the model of Figure 3 at each site. Altemative model responses plotted with dashes and dots are discussed in the text. Data were collected using the UURI broadband system.

longer periods than observed. The calculated $\phi_{y x}$ of this test is in fact much weaker now at $1 \mathrm{~km}$ than that observed at 48 $\mathrm{km}$, which is in opposition to the measured case. These lower phases at $1 \mathrm{~km}$ are a result of close proximity to the ocean. Being able to specify a priori the seawater response in the finite element model increases our resolving capability under the Coast Range.

The next test fixes the layer depth at the coastline and reduces the dip inland to $10^{\circ}$ such that the layer depth at $y=$ $48 \mathrm{~km}$ is about $20 \mathrm{~km}$ rather than $32 \mathrm{~km}$ as in Figure 3. Resulting is the dotted curve "c" in Figure 12 which peaks at somewhat shorter periods than observed. We therefore conclude that the dip exceeds $10^{\circ}$ and the preferred value is approximately $20^{\circ}$.

The dotted curve " 3 " at $y=1 \mathrm{~km}$ in Figure 12 demonstrates the effect of electrically disconnecting the dipping Coast Range conductor from the trench offshore. This disconnection was made by setting the resistivity of the layer from the trench to about $15 \mathrm{~km}$ offshore to $300 \mathrm{ohm} \mathrm{m}$, the value of the material above and below it. The calculated $\phi_{y x}$ again falls far below that observed and cannot be reconciled by making the remainder of the Coast Range conductor less resistive. The final Coast Range test is for existence of the low conductance $(<100 \mathrm{~S}$ ) portion of the dipping conductor. This is demonstrated by removing it east of about $y=20 \mathrm{~km}$ and replacing it with background material of $350 \mathrm{ohm} \mathrm{m}$. Such an alternative fails to reproduce the subtle phase peak in this area (dashed response "b").

A deep conductive root connecting the base of the Willamette Basin sediments to the western portion of the deep subhorizontal conductor appears in the minimumstructure resistivity cross section of Jiracek et al. [this issue]. We examine this possibility, which is in contrast to our model, in the lower panel of Figure 12. The computed response of our model (solid curve "A") is compared to the computed response of Jiracek et al. (dashed curve "B"). Our model appears to fit the data somewhat better. However, the error bars below $10 \mathrm{~s}$ are quite large and it seems premature to rule out some electrical connection. These errors result from strong cultural EM interference in this area. Since such a connection would have profound tectonic implications, it is important to remeasure several sites in this period range using a fully remote reference MT system.

Resolution of resistivity structure offshore by its effect on the vertical magnetic field is examined in Figure 13. The data quality at $T<20 \mathrm{~s}$ is not the best, but fortunately most of the response occurs at longer periods. The fit of the preferred model to the data is reasonably good. Note that both data and calculations show slight inflections in $\operatorname{Re}\left(M_{2 y}\right)$, with complementary behavior in $\operatorname{Im}\left(M_{z y}\right)$, around $1000 \mathrm{~s}$ period. When the sedimentary distributions of both the near-offshore Newport Basin and the abyssal Cascadia Basin are removed by setting them to $300 \mathrm{ohm} \mathrm{m}$, we obtain the response of the seawater alone (dotted curves). The seawater is quite insufficient by itself to explain the measured vertical field. The dashed response occurs when the abyssal sediments are present and only the nearby Newport Basin is removed. We see that this basin is very important in determining the vertical field on land near the coast. If the oceanic upper mantle conductor in Figure 3 is not extended east of the coast, the misfit is about 0.05 worse below $500 \mathrm{~s}$, with the computed values of $\operatorname{Re}\left(M_{z y}\right)$ being too large.
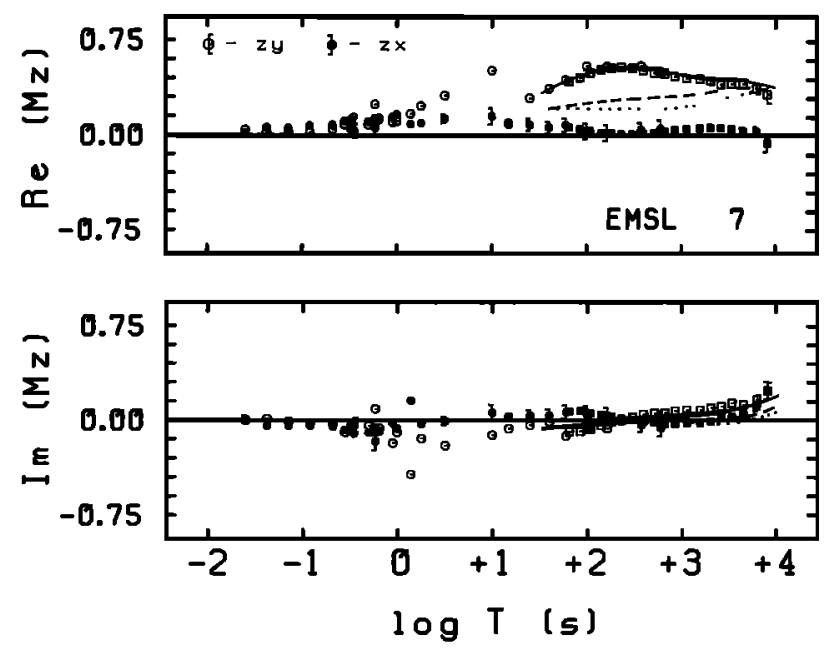

Fig. 13. Real and imaginary observed response curves for elements $M_{2 x}$ and $M_{x y}$ measured by University of Oregon and GSC about $7 \mathrm{~km}$ inland on the Lincoln Line. Computed responses include that of the best model (solid), that with low-resistivity sediments of the Newport Basin removed (dashes), and that with only the seawater present (dots). 
The vertical magnetic field measured on the seafloor at site SF1 is compared to that due to the model of Figure 3, where the agreement is good, plus those of two altemative structures (Figure 14). The first altemative contains very conductive (2 ohm $\mathrm{m}$ ) sedimentary material throughout the whole melange and down the trench to a distance of about $15 \mathrm{~km}$ from the shoreline. Such a structure drastically curtails the peak response at SF1, and even more at SF2, and moves the peak to longer periods (dashed curves). Second, removal of all low resistivity material except the seawater results in a real component of vertical field at SF1 that increases to large values at periods much less than the shortest measured (dotted curves in Figure 14). Disagreement between observed and computed $\operatorname{Im}\left(M_{z y}\right)$ is large in this case also.

Negative values of $\operatorname{Re}\left(M_{2 x}\right)$ develop beyond $10^{4} \mathrm{~s}$ in Figure 14 and all other seafloor sites on the Lincoln Line. This behavior implies higher resistivities of regional extent south of our oceanic profile. A similar character to $M_{2 x}$ is observed on the land also.
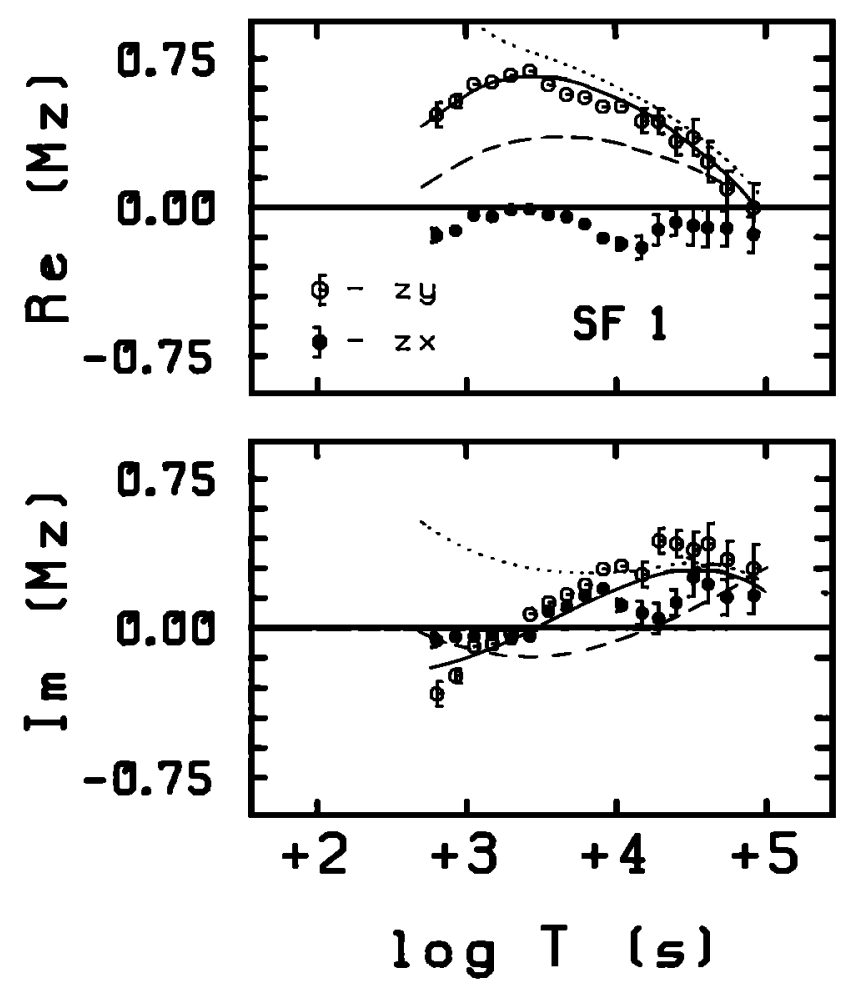

Fig. 14. Real and imaginary responses for $M_{z y}$ and $M_{z y}$ observed at ocean bottom site SF1. Error bars are one standard deviation where they exceed the size of the plotting symbols. Computed responses include those of the model of Figure 3 (solid), that with the melange and trench sediments given a resistivity of $2 \mathrm{ohm} \mathrm{m}$ (dashes), and that with only the seawater present (dots).

The fit of the model to the measurements in the vicinity of the Juan de Fuca ridge is examined more closely in Figure 15. Note that the agreement of the preferred model calculations (solid curves) with both $\phi_{x y}$ and $\phi_{y x}$ is good at almost all periods but that the calculated apparent resistivities $\rho_{x y}$ and $\rho_{y x}$ are lower than observed for periods greater than $10^{4} \mathrm{~s}$. If the apparent resistivities are fit at the longest periods, then the calculated phases are lower than observed at periods longer than $3000 \mathrm{~s}$ (dashed curves). The latter model has resistivities near $20 \mathrm{ohm} \mathrm{m}$ extending all the way to $400 \mathrm{~km}$ depth. This data inconsistency exists for all five seafloor MT stations on the Lincoln Line and remains a serious issue for the deep oceanic structure. Non-planar source fields which have escaped robust processing are a possible explanation [but see Bahr and Fillowx this issue], or perhaps some other form of bias error is present.

Our measurements appear only weakly sensitive to the resistivity of the oceanic lithosphere, in part because the data do not extend to short enough periods but also due to the nature of the ocean-continent resistivity transition. Ranganayaki and Madden [1980] show that the high ocean lithosphere resistivity, if contiguous with high resistivity under the continents, can strongly depress electric fields and thus apparent resistivities on the seafloor at long periods by restricting current flow in the overlying seawater. However, in the Juan de Fuca region, low resistivity material extending down the subduction decollement as in Figure 3 or beneath Vancouver Island [Kurtz et al., 1986] provides an electrical pathway between the ocean and low regional resistivity beneath North America.

One alternative model that seems clearly inconsistent with the data has resistivity in the oceanic mantle conductor falling steadily with depth from $30 \mathrm{ohm} \mathrm{m}$ to $10 \mathrm{ohm} \mathrm{m}$ at 90 $\mathrm{km}$ and to $3 \mathrm{ohm} \mathrm{m}$ at $215 \mathrm{~km}$. The calculated $\rho_{x y}$ falls too uniformly and the calculated $\phi_{x y}$ remains too constant to agree with the measurements (dotted curves). Note that the differences between the various model responses in Figure 15 are significantly greater for the TE mode than the TM. This could be expected because we are testing deep model features which terminate laterally near the coast. Limiting the lateral extent of the deep structure this close to the seafloor profile reduces the TM mode response more than the TE. We therefore are presuming that off-line (three-dimensional) effects are not influencing the seafloor TE data as much as the range of our test computations.

\section{TECTONIC IMPLICATIONS OF RESISTIVITY STRUCTURE}

The electrical resistivity structure of the Juan de Fuca subduction system is a function of the chemical composition and physical state of that system. However, a particular value of resistivity can result from a plurality of mechanisms [see reviews by Brace, 1971; Olhoeft, 1981; Shankland et al., 1981; Shankland and Ander, 1983; Wannamaker, 1986; Hyndman, 1988]. Therefore it is usually not possible to produce a unique interpretation of resistivity without independent geophysical and geological constraints. There exist a good many constraints for EMSLAB on upper crustal structure, seismic velocity, the geotherm, and subducted slab mineralogy. Within this framework, electrical resistivity may augment our understanding of volcanic structure and history, sediments and pore water during subduction, evolution and migration of fluids during deep metamorphism, and the distribution of melt in the upper mantle.

\section{Upper Crustal Structure on Land}

Model resistivities in Figure 3 of about $100 \mathrm{ohm} \mathrm{m}$ or less for the Siletz River marine volcanics of the Coast Range are representative of basalt formations near-surface. However, 


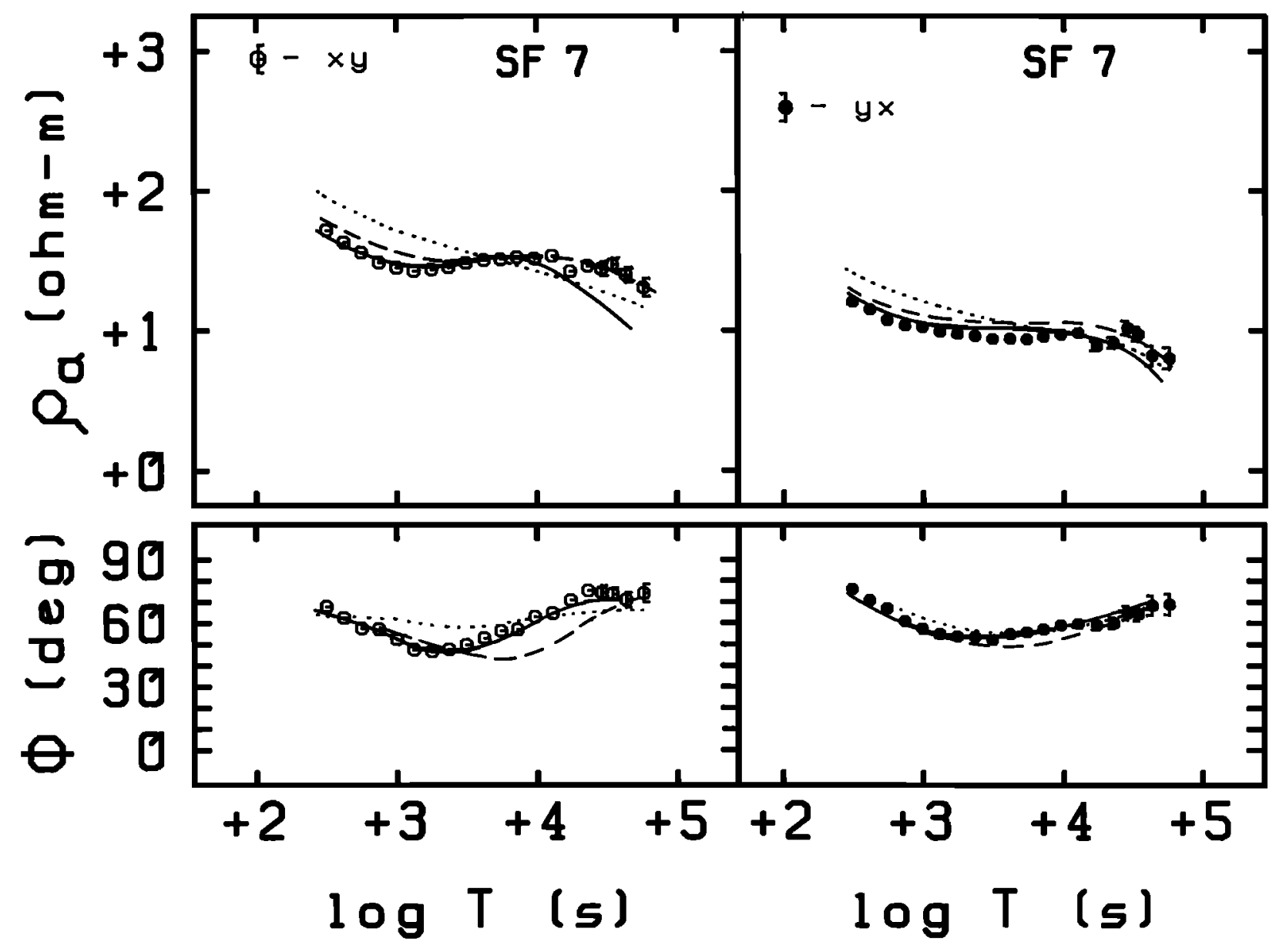

Fig. 15. Apparent resistivity and impedance phase data at ocean bottom site SF7 compared to the computed response of the model of Figure 3 (solid curves, both modes). Error bars are one standard deviation plotted where larger than data symbol. Note the inconsistency in apparent resistivity and impedance phase for $T \geq 10^{4} \mathrm{~s}$, where we cannot fit the former without giving misfit to the latter.

the conductive layer around $2 \mathrm{~km}$ depth below this unit suggests a change in lithology. The Siletz River basalts were extruded over preexisting oceanic crust starting in the Paleocene [Snavely, 1987]. The conductor may represent sediments deposited below the Siletz River formation or within it during a hiatus in igneous activity. Later intrusive igneous events during the Miocene [Baldwin, 1981] may have further reduced resistivity by hydrothermal alteration.

The large volume of sedimentary material of the Willamette Basin constitutes the most important upper crustal resistivity inhomogeneity on the landward segment of the Lincoln Line. Marine units of Eocene through Oligocene age comprise the volumetrically greatest proportion of sediments especially of the western portion of the basin [Wells and Peck, 1964] and possess resistivities in the range of $10-15 \mathrm{ohm} \mathrm{m}$ in the model. Toward the east, pyroclastic volcanics of Oligocene and Miocene age of Western Cascades affinity dominate the stratigraphy [Verplanck and Duncan, 1987] and also are in the range $10-15 \mathrm{ohm} \mathrm{m}$. The relatively restricted occurrence of Columbia River basalts near the center of the basin probably is represented by members of the Grande Ronde Formation and locally the Wanapum Basalt [Baldwin, 1981]. The variation in the basement profile of our resistivity model in Figure 3, particularly the horst-like feature near $y=100 \mathrm{~km}$, is suggested also in the cross-sections of Couch and Riddihough [1989, in press] derived from gravity and drilling and of Hermance et al. [1989, in press] from their profile of geomagnetic variation observations.

Beneath the eastem portion of the Western Cascades, the volcanic strata were extensively intruded by the Halls Diorite Porphyry of early Miocene age [Baldwin, 1981] which probably contributes to the high model resistivities at shallow depths here. The shallow conducting layer commencing near Detroit Lake $(y=150 \mathrm{~km}$ in Figure 3) and continuing eastward is tentatively correlated with unwelded tuffaceous units of the Breitenbush formation [Priest et al., 1983, 1987]. The overlying more resistive unit is mainly middle to late Miocene lavas of late Westem Cascades association. The western boundary of the conductor appears to coincide with a major N-NE trending graben fault, known as the Hoover fault in this area [Priest et al., 1987], which is part of the regional system separating the downdropped High Cascades graben from the relatively uplifted Western Cascades block [Priest et al., 1983; Smith and Taylor, 1983].

The abrupt increase in conductance of the shallow conductive layer east of the High Cascades axis suggests that different or additional lithologies are present. The MT stations east of Mount Jefferson lie a good $10 \mathrm{~km}$ south of the 
peak and cross an area of anomalously low Bouguer residual gravity [Couch et al., 1982; Smith and Taylor, 1983; Smith et al., 1987]. The low resistivity both within the eastem portion of the High Cascades graben and east of the bounding Green Ridge fault in the Deschutes Basin thus may represent an accumulation of tuffaceous material from ancestral High Cascades volcanic centers nearby or from an early Pliocene silicic volcanic "highland" some $50 \mathrm{~km}$ to the south [Smith and Taylor, 1983]. The conductor is covered now by resistive basaltic rocks of the upper Deschutes Formation of the early High Cascades volcanic episode [Priest et al., 1983]. That the conductive layer does not appear significantly deeper west of Green Ridge fault than to the east indicates that late High Cascades volcanics erupted after formation of the graben are not very thick in this area.

We believe that the MT data have not resolved significant lateral variations within the middle crust underlying the land segment of the Lincoln Line. Thus no new light has been shed on the boundary between Mesozoic and older rocks comprising the deep basement of central Oregon and the early Cenozoic oceanic rocks presumably forming the deeper crust of western Oregon [e.g., Couch and Riddihough, 1989, in press]. Resistivity values of hundreds of ohm $\mathrm{m}$ are typical of a wide range of lithologies with water-saturated, interconnected porosities below $1 \%$. Delineation of any terrane boundary is hampered both by limitations on the twodimensional assumption and by limitations on data quality especially in the culturally developed Willamette Basin.

\section{Deep Crust and Upper Mantle on Land}

Discussion in this section focuses on the deep conducting layer a few tens of kilometers below nearly all of the Lincoln Line on land. Under the Coast Range and westernmost Willamette Basin, the thin conductor is presumed to represent, at least in part, pore water or sediments along or near the interface between the subducting Juan de Fuca plate and the overriding North American continent. This parallels the interpretation of Kurtz et al. [1986] on Vancouver Island where a similar thin conductor was resolved using MT. In their study, interconnected porosities of one to a few percent were inferred by assuming fluids of seawater salinity or greater. A similar inference can be made for the layer beneath the Coast Range (Figure 3). Interconnected porosities of 1$2 \%$ would result for the interval $y=20-60 \mathrm{~km}$ where the conductance is less than $100 \mathrm{~S}$ but might reach $10 \%$ for the portion west of $y=20 \mathrm{~km}$ whose conductance may approach $1000 \mathrm{~S}$. Alternatively, this higher conductance in part may represent a greater layer thickness.

In addition to possible subducted sediments or pore waters, fluids released during mineral devolatilization reactions may reduce resistivity here. Constraints on the geotherm and alteration mineralogy of the subducted slab are needed to decide which reactions could be taking place [e.g., Wannamaker, 1986; Hyndman, 1988]. Heat flow and crustal heat production of westem Oregon are similar to those of southwestern British Columbia [Blackwell and Steele, 1983; Lewis et al., 1988; Couch and Riddihough, 1989, in press] so that some calculations performed for the latter region can be made use of in EMSLAB. Accordingly, temperatures in the range of $250-500^{\circ} \mathrm{C}$ appear appropriate for the depth interval $12-30 \mathrm{~km}$ of the dipping Coast Range conductor. As noted by
Hyndman [1988], prograde metamorphic conditions which the subducting slab encounters favor the transition from blueschist or zeolite to greenschist facies with attendant release of water. Most of this dewatering may occur west of $y=20 \mathrm{~km}$, where the more conductive portion of the Coast Range conductor resides, although this latter feature may in part also represent a greater abundance of subducted sediments. Further updip under the melange and Newport Basin area, breakdown of clays might be another source of water.

The dipping conductive layers inferred beneath the Oregon Coast Range and beneath Vancouver Island [Kurtz et al., 1986] have been interpreted not to exist precisely at the plate interface but instead to represent fluids risen buoyantly from the plate surface and trapped below an impermeable boundary above [Hyndman, 1988]. This boundary would be formed by hydration of minerals by the fluids or by precipitation of silica from the fluids as they cool. The dip of the conductor under Vancouver Island has been correlated with dip of the isotherms, in particular the $450^{\circ} \mathrm{C}$ isotherm, in accordance with decreasing heat flow eastward. In contrast, dip of the isotherms is not resolved by the sparse heat flow data from western Oregon [Blackwell and Steele, 1983; Couch and Riddihough, 1989, in press] while inland dip of the Coast Range conductor evidently is. Also, based on COCORP seismic reflection profiling about $30 \mathrm{~km}$ south of the Lincoln Line, Keach et al. [1989] interpret the subduction decollement of the Juan de Fuca plate to lie at a depth near $35 \mathrm{~km}$ some 50 $\mathrm{km}$ inland. This is essentially coincident with our dipping conductive layer at a corresponding distance from the coast, at least within the uncertainties involved. The EMSLAB results therefore do not unequivocally support the notion of rising fluids beneath the Coast Range trapped at a dipping boundary significantly above the subduction slip plane.

Fluids are offered also as an explanation for the subhorizontal zone of high conductance extending east from $y=60 \mathrm{~km}$ to the High Cascades axis (Figure 3). We suggest that this pronounced conductor represents primarily a concentration of water-rich fluids which have risen buoyantly from the surface of the subducted plate where further dehydration reactions are taking place. The upper limit of this fluid migration, i.e., the top of the conductor, we interpret to be controlled by temperature. Heat flow data in Oregon [Couch and Riddihough, 1989, in press] suggest a temperature around $450^{\circ} \mathrm{C}$ for the top of the conductor. Such a temperature appears appropriate for the mineral hydration and silica precipitation mechanisms of permeability sealing mentioned previously. Furthermore, the rheology of the host rock becomes increasingly stiff toward shallower levels due to lower temperatures [Kirby, 1983]. The temperatures over most of the conductor appear too low to support hydrous melting, but more accurate heat flow data to characterize the geotherm in this area are highly desirable.

To understand which hydrous minerals may be breaking down to contribute the fluid, we need again to constrain temperature at the subducted plate surface. However, it is hazardous to extrapolate a conductive geotherm beyond the strong conductor being considered. Heat absorbed in dehydration at the slab, hot fluids migrating upward, and heat producing hydration reactions at higher levels and within the conductor may constitute significant advective heat flow [Anderson et al., 1976; Lewis et al., 1988]. This would tend 
to reduce the geothermal gradient below the electrical conductor. At the easternmost end of the dipping weaker conductor of the Coast Range, i.e., just before the start of the low-resistivity region under discussion, a conductive geotherm suggests temperatures of $550-600^{\circ} \mathrm{C}$. If this is approximately representative, it implies dehydration of greenschist facies minerals as the cause of the strong conductor at least near its westem end around $y=60 \mathrm{~km}$. This interpretation of the fluid source is consistent with the observation that greenschist minerals, especially chlorite, carry the bulk of the chemically bound water in subducted oceanic crust [Humphris and Thompson, 1978; Ito et al., 1983].

Breakdown of hydrous minerals generally is incongruent so that fluid release occurs over a finite temperature interval [e.g., Etheridge et al., 1983]. The interval of breakdown of greenschist facies may be broadened further if serpentine and epidote, commonly observed also, are included. A finite interval of breakdown temperature translates to a region of fluid release and upwelling which is of finite lateral extent, especially over a plate whose angle of subduction is not very steep. The lateral extent of fluid release may be increased yet more through the buffering of temperature along the slab surface by the dehydration reactions themselves [Anderson et al., 1976].

As we look farther downdip, more refractory hydrate minerals of upper greenschist and amphibolite facies should not breakdown to release $\mathrm{H}_{2} \mathrm{O}$ fluid directly but instead produce water-undersaturated melts through vapor-absent fusion [Burnham, 1979; Wyllie, 1979; Wannamaker, 1986]. The water-bearing melts themselves may rise through the overlying mantle wedge and crystallize as they lose heat or encounter the $\mathrm{H}_{2} \mathrm{O}$-saturated solidus at lower pressures. This process, in essence, merely complicates the migration of fluid to higher levels. Nevertheless, melts are believed to be more effective metasomatic agents than fluids [Eggler, 1987] so that more substantial upward movement of alkalis and incompatible elements may be occurring here. The strong horizontal conductor and its interpretation may have an analog in the model of Kurtz et al. [1986] where a thick conductive region at a similar depth lies below mainland British Columbia. It may also be manifest seismically in the low velocity zone interpreted beneath the Willamette Basin region by Langston [1977].

The model of hydrous mineral breakdown and fluid release presented here helps explain the imbalance noted by Ito et al. [1983] between the amount of $\mathrm{H}_{2} \mathrm{O}$ contained in altered oceanic crust and the much lesser amount released during arc magmatism. Our interpretation is that most of the water in the altered ocean crust is liberated well before the volcanic arc is reached. Also, the model of this paper is similar to that of Fyfe and McBirney [1975] but with one important difference. The facies breakdown boundaries described here are a full metamorphic grade lower than those of Fyfe and McBirney [1975] at corresponding positions between the trench and arc. Significant uplift due to volumetric expansion from hydration reactions between released fluid and mafic minerals overlying the subducted plate is interpreted to affect the Western Cascades and eastern Willamette Basin by Fyfe and McBirney [1975]. An unknown portion of the released fluid may not be absorbed in hydration but perhaps reaches crustal levels and eventually the hydrosphere. Our resistivity cross section more closely ressembles a petrological model of subduction reviewed by Wyllie [1988], wherein oceanic crust whose surface is cooled by endothermic dehydration is subducted below a mantle wedge warmed by induced convection.

Next we consider the conductive axis extending up from the east end of the strong, horizontal conductor just described around $y=160 \mathrm{~km}$. Its depth to top, about $5 \mathrm{~km}$, may represent the upper limit of development of andesitic magmas within the crust according to Anderson [1982]. We doubt that this midcrustal conductor results primiarily from the presence of silicate melt in large volume but rather from hydrothermal fluids exsolved during repeated intrusion and crystallization. It is not clear what structural controls cause this conductor to be centered just west of the present andesitic arc instead of directly beneath it. However, numerous basaltic vents and vent lineaments also have developed this far west of the arc in the last $5 \mathrm{~m} . \mathrm{y}$. in response to a relaxation of regional compressive forces [Hughes and Taylor, 1986]. The presence of the conductive axis has been detected also to the north of our line near Breitenbush Hot Springs and to the south near the latitude of Mount Washington from the MT profiling of Stanley et al. [1989]. While the depth of this zone is somewhat beyond that currently considered viable for geothermal resources, its substantial size may warrant evaluation for future energy needs.

As noted already, a broad three-dimensional effect has complicated the determination of deep resistivity structure under the Deschutes Basin using a two-dimensional interpretation procedure. The nature of the three-dimensional effect suggests a roughly E-W transition to lower resistivity south of the Lincoln Line. A similar structure is implied in the geomagnetic array study of Gough et al. [this issue] where resistive lithosphere of the Blue Mountains block, including the Deschutes Basin, lies north of the more conductive Basin and Range province [Gough, 1983; Wannamaker, 1983]. This transition may be marked at the surface by the Brothers fault zone and a coincident trend of Late Pliocene to present volcanic vents oriented ESE [Guffanti and Weaver, 1988]. The magnetotelluric and geomagnetic data together suggest that the Brothers fault zone may be a better choice for the northem limit of recent Basin and Range activity than is the SW-NE trending Klamath-Blue Mountains lineament [cf. Eaton et al., 1978; Riddihough et al., 1986]. Further threedimensional analysis and data acquisition is sought to better define the back-arc electrical asthenosphere as teleseismic results imply low velocity in this area extending to $200 \mathrm{~km}$ depth [Rasmussen and Humphries, 1988].

\section{Implications of Seafloor Resistivity Structure}

The resistivities of the thick sedimentary layering of the abyssal plain (Cascadia Basin) and on the continental shelf (Newport Basin) are strikingly low, 1-2 ohm m (Figure 3). These values are in keeping, however, with very high porosities observed in drilling of accretionary complexes which range from 25 to $75 \%$ in the upper $2 \mathrm{~km}$ [Kulm et al., 1973; Bray and Karig, 1985]. In contrast, such low resistivities cannot exist throughout the melange and subducted trench sediments without causing a vertical magnetic field response much smaller than observed (Figure 14). Our magnetotelluric results therefore appear to sense the off-scraping of seafloor sediments or the porosity reductions attending sediment dewatering during subduction. The 
primary pathways for dewatering appear to be along the decollement between the subducted plate and the overlying accretionary wedge as well as up thrust faults in the wedge [Kulm et al., 1986; Moore et al., 1987]. The final resistivity from the imbrication and dewatering process as represented by the Miocene melange and broken formation is in the tens of ohm $\mathrm{m}$ at least and suggests bulk porosity reductions of a factor approaching 10 .

The nominal value of $3000 \mathrm{ohm} \mathrm{m}$ for seafloor lithospheric resistivity in Figure 3 may be a minimum. Resistivities in the thousands of ohm $m$ have been inferred for depths greater than $1 \mathrm{~km}$ below the seafloor from active source electromagnetic surveying as well [Young and Cox, 1981]. Traces of water may be responsible for these values in the middle oceanic crust, while thermally activated rock semiconduction is probably the mechanism of resistivity at greater depths. It was noted earlier that the resistivity of the ocean lithosphere is hard to resolve here in large part due to low-resistivity material extending down the subduction decollement beneath the continent. Subduction surrounds almost the entire Pacific Ocean so, to obtain better estimates of ocean lithosphere resistivity using MT, a profile of soundings should be carried out across a continental margin in the Atlantic.

The low resistivity beyond about $35 \mathrm{~km}$ depth below the seafloor (Figure 3 ) is proposed to represent partial melt beneath the Juan de Fuca plate. To relate values of resistivity to degree of partial melting, we assume first that temperature within the melt zone is buffered near the volatile-free peridotite solidus by the process of adiabatic upwelling and fusion [Mysen and Kushiro, 1977; Wyllie, 1979, 1988; Oxburgh, 1980]. An estimate of melt fraction can be made thereby using the tholeiite liquid conductivity measurements of Tyburczy and Waff [1983] together with an appropriate mixing law relating bulk conductivity to the conductivities of the melt and host mineral phases. The mixing law employed here is the grain edge tubule model discussed by Shankland et al. [1981] and von Bargen and Waff [1986] which represents the equilibrium texture of melt distribution in olivene-basalt melt systems. The olivene data of Duba et al. [1974] are used for the solid-state conductivity of the mineral phase.

Near the top of the low resistivity region in the oceanic upper mantle, a melt fraction of about $7 \%$ is implied from a resistivity value of $20 \mathrm{ohm} \mathrm{m}$. As depth increases, this fraction falls due mainly to increasing melt conductivity with increasing solidus temperature but also to increasing olivene conductivity especially below $100 \mathrm{~km}$ depth. The computed melt fraction is about $3 \%$ at $75 \mathrm{~km}$ depth, just under $1 \%$ at 125 $\mathrm{km}$, and becomes zero by $200 \mathrm{~km}$ depth where olivene solidstate resistivity at $1700^{\circ} \mathrm{C}$ has fallen to $20 \mathrm{ohm} \mathrm{m}$. A reasonably good comparison exists between our conductivity model and seismic models of young (0-20 m.y.) oceanic plates, of which the Juan de Fuca beneath our profile is one. Sato et al. [1988], in their compilation of shear wave models, suggest a few percent partial melt to depths of about $150 \mathrm{~km}$. Laboratory and theoretical investigations of partial melting also suggest that melting should have similar effects on conductivity and velocity [Shankland et al., 1981]. Our data do weigh against resistivity decreasing steadily in the oceanic asthenosphere (Figure 8) which would have suggested an interconnected melt fraction of $1 \%$ persisting from 75 to over $300 \mathrm{~km}$ depth [cf. Anderson, 1987]. We note in addition that the termination of this asthenosphere a moderate distance inland agrees with the P-wave tomographic image of Rasmussen and Humphries [1988] which implies a transition to a deep, high-velocity root in the mantle from below the central Willamette Basin to the High Cascades.

The higher resistivities of regional extent south of the Lincoln Line on the seafloor implied by the vertical magnetic field may reflect lower temperatures at depth south of the Blanco fracture zone. These in turn are suggested from the greater bathymetric depths in the vicinity of the Gorda Ridge. An explanation for higher regional resistivity to the south on the landward portion of our profile is unclear at present.

A physical explanation for very low model resistivity below $215 \mathrm{~km}$ in the oceanic upper mantle is problematic. While its mere existence is questionable given the data inconsistency discussed previously, very low resistivities at depths less than $300 \mathrm{~km}$ have also been interpreted beneath the East Pacific Rise spreading center [Filloux, 1982] and beneath Hawaii, a site of presumed hot spot activity [Larsen, 1975]. These depths appear too shallow to be correlated with the olivene-spinel phase transition [Akimoto and Fujisawa, 1965] occurring near $400 \mathrm{~km}$. One possibility for these very low resistivities is a deep region of additional melting in an olivene eclogite source composition [Anderson, 1987; Wyllie, 1988]. Added thermal impetus for deep melting below the Juan de Fuca spreading center may come from its proximity to the Cobb hot spot [Karsten and Delaney, 1989]. If mantle resistivities down to $400 \mathrm{~km}$ depth remain in the range $15-20 \mathrm{ohm} \mathrm{m}$ however, as the apparent resistivity alone suggests, then no such deep melting is implied. These higher resistivities would be consistent with solid-state semiconduction in olivene along a near-adiabatic temperature profile of $1700-1800^{\circ} \mathrm{C}$ from $200-400 \mathrm{~km}$ depth. This is an important alternate model of the deep physicochemical state in regions of mantle upwelling and fusion [Wyllie, 1988] that our magnetotelluric measurements cannot clearly distinguish at present. This underscores a need for obtaining reliable plane wave impedance estimates to very long periods, $3 \times 10^{4}$ s at least.

\section{Conclusions}

The inferences drawn from interpreting the Lincoln Line observations in EMSLAB fall into two broad categories; those on the physicochemical state of the young Juan de Fuca plate and its subduction beneath Oregon, and those concerning the two-dimensional modeling of MT data in environments which depart somewhat from the twodimensional assumption. Regarding the former, measurements on the seafloor indicate very low resistivity in the eastward thickening sedimentary wedge of the abyssal Cascadia Basin provided its depth extent is constrained by marine seismic sections. The majority of these sediments are inferred to be off-scraped or lose most of their interstitial water before being carried more than ten or so kilometers down the trench. In the oceanic upper mantle, of the Juan de Fuca plate, moderately low resistivities presumably reflect up to several percent partial melt attending regional upwelling in the vicinity of the ridge. Very low resistivities modeled below $215 \mathrm{~km}$ depth in the oceanic mantle are hard to explain physically but problems with the very long-period data hamper the modeling here.

On land, upper crustal resistivity structure indicates the cumulative and ongoing effects of plate convergence and 
volcanism. Residual sediments, pore waters, possibly sulfides, and dehydrating altered ocean crust carried down the subduction zone appear to produce a low resistivity upper mantle layer, albeit a subtle one, dipping about $20^{\circ}$ eastward beneath westernmost Oregon. The position of this layer appears consistent with the Juan de Fuca plate subduction decollement. Farther inland and downdip at appropriately high P-T conditions, a massive breakdown of greenschist minerals is hypothesized to liberate most of the water carried in the ocean crust alteration well before the volcanic arc is reached. This fluid release produces a strong, subhorizontal conductor with a depth to top of about $25 \mathrm{~km}$. The resistivity manifestation of the arc magmatism itself is not strong, but consists of a low resistivity axis in the middle crust below and to the west of the arc at the surface. It presumably represents mainly fluids released from crystallizing magmas and should be considered for its geothermal energy significance. North central Oregon is resistive at depth compared to the crust and upper mantle to the south and it is suggested that the Brothers fault zone marks an electrical, and thus possibly a thermal and magmatic, boundary with the northern Basin and Range.

Regarding the derivation of the resistivity cross section from the observations, the strong N-S preferred orientation of most structures in the region has allowed successful twodimensional modeling of data approximating the TM mode. A fixed north-oriented $x$ axis was essential in clarifying the subtle anomalies due to subduction structure. The vertical magnetic field, however, confirmed many structures derived using the TM impedance functions and also was sensitive to narrow conductors such as the midcrustal axis beneath the High Cascades. It was also important in establishing the resistivity of the sedimentary sections offshore and the conductance of the oceanic asthenosphere. On the land, the data corresponding to the TE mode exhibit a variety of threedimensional effects including shallow statics, finite strike length of regional features, and some strongly threedimensional behavior at very long periods which is difficult to explain. A fruitful area for three-dimensional modeling could be the Deschutes Basin region of the Blue Mountains resistive block to better establish the depth extent of the backarc electrical asthenosphere. On the seafloor, the much greater lateral uniformity of structure near-surface has allowed reasonably good fits to both modes of impedance plus the vertical field down to $10^{4} \mathrm{~s}(\sim 200 \mathrm{~km}$ depth) but not more.

The unprecedented data quality achieved in the EMSLAB project has allowed a geophysical interpretation which is similarly unparalleled in scope and detail from induction studies. Nevertheless, several data collection and interpretation needs for the future of MT have been highlighted by our experiment. Strong cultural noise and near-field effects often correlated over several kilometers compromised resolution beneath the Willamette Basin. These can only be overcome using a remote reference at distances exceeding the correlation length of the noise. A more flexible approach to electric field collection, or even continuous $E$ field profiling (e.g., EMAP) locally, would efficiently meet data sampling requirements especially over volcanic rocks. Many more details of trench structure beneath the near-offshore continental shelf could be revealed if the logistics of shallow water MT were worked out. Characterization of the oceanic lithosphere would be greatly enhanced by extending the seafloor data bandwidth to shorter periods using more sensitive magnetometers and precise timing control. Better processing to remove source effects or bias may be needed to achieve good data at periods beyond $10^{4} \mathrm{~s}$ and resolve structure in the $200-500 \mathrm{~km}$ depth range. Finally, addition of independent geological knowledge can substantially increase the information that can be extracted from induction data. For example, incorporating the ocean bathymetry and resistivity permitted determining the dip of the conductor under the Coast Range. Thus inversion algorithms that in the future may replace the laborious modeling process carried out in this paper should allow for such independently defined constraints.

Acknowledgments. The modeling and interpretation of this paper were supported by the U.S. National Science Foundation under grants EAR-8410638, 8512895 and 8708382. Many valuable discussions were held with Richard W. Couch and George R. Jiracek Financial assistance for publication costs was provided by AT \& T Bell Laboratories, Geological Survey of Canada, and University of Washington. Philip E. Wannamaker is grateful to the San Diego Supercomputing Center and the University of Utah for access to the SDSC Cray XM-P under the University Block Grants program. This is Geological Survey of Canada Contribution 23489.

\section{REFERENCES}

Akimoto, S.-I., and H. Fujisawa, Demonstration of the electrical conductivity jump produced by the olivene-spinel transition, $J$. Geophys. Res., 70, 443-449, 1965.

Anderson, A. T., Jr., Parental basalts in subduction zones: Implications for continental evolution, J. Geophys. Res., 87, 7047-7060, 1982.

Anderson, D. L., The depths of mantle reservoirs, in Magmatic Processes: Physicochemical Principles, edited by B. O. Mysen, Spec. Publ. 1, pp. 3-12, The Geochemical Society, Dayton, Ohio, 1987.

Anderson, R. N., S. Uyeda, and A. Miyashiro, Geophysical and geochemical constraints at converging plate boundaries, part I, Dehydration in the downgoing slab, Geophys. J. R. Astron. Soc., 44, 333-357, 1976.

Bahr, K., and J. H. Filloux, Local Sq response functions from EMSLAB data, J. Geophys. Res., this issue.

Baldwin, E. M., Geology of Oregon, 3rd ed., 170 pp., Kendall/Hunt, Dubuque, Iowa, 1981.

Banks, R. J., The overall conductivity distribution of the Earth, $J$. Geomagn. Geoelectr., 23, 337-351, 1972.

Blackwell, D. D., and J. L. Steele, A summary of heat flow studies in the Cascade Range, Geotherm. Resour. Counc. Trans., 7, 233-236, 1983.

Bostick, F. X., Jr., Electromagnetic array profiling (EMAP), extended abstract of paper presented at the 56th annual meeting of the Soc. of Explor. Geophys., Houston, Tex., 1986.

Brace, W. F., Resistivity of saturated crustal rocks to $40 \mathrm{~km}$ based on laboratory measurements, in The Structure and Physical Properties of the Earth's Crust, Geophys. Monogr. Ser., vol. 14, edited by J. G. Heacock, pp. 243-256, AGU, Washington, D. C., 1971.

Bray, C. J., and D. E. Karig, Porosity of sediments in accretionary prisms and some implications for dewatering processes, J. Geophys. Res., 90, 768-779, 1985.

Bumham, C. W., Magmas and hydrothermal fluids, in Geochemistry of Hydrothermal Ore Deposits, 2nd ed., edited by H. L. Bames, pp. 17136, John Wiley, New York, 1979.

Couch, R. W., G. S. Pitts, M. Gemperle, D. E. Braman, and C. A. Veen, Gravity anomalies in the Cascade Range in Oregon: Structural and thermal implications, OF Rep. 0-82-9, Oreg. Dep. of Geol. and Miner. Ind., 43 pp., Portland, 1982.

Couch, R. W., and R. P. Riddihough, The westem continental margin of N. America: Baja Califomia to the Queen Charlotte Islands, in Geophysical Framework of the United States, GSA Monogr. Ser., vol. X, edited by W. Mooney and L. Pakiser, Geological Society of America, Boulder, Colo., in press, 1989.

DeLaurier, J. M., D. R. Auld, and L. K. Law, The geomagnetic response across the continental margin off Vancouver Island: Comparison of results from numerical modeling and field data, J. Geomagn. Geoelectr., 35, 517-528, 1983. 
Duba, A., H. C. Heard, and R. N. Schock, Electrical conductivity of olivene at high pressure and under controlled oxygen fugacity, $J$. Geophys. Res., 79, 1667-1673, 1974.

Eaton, G. P., R. R. Wahl, H. J. Prostka, D. R. Mabey, and M. D. Kleinkopf, Regional gravity and tectonic patterns: their relation to late Cenozoic epeirogeny and lateral spreading in the westem Cordillera, in Cenozoic Tectonics and Regional Geophysics of the Western Cordillera, edited by R. B. Smith and G. P. Eaton, Mem. Geol. Soc. Am., 152, 51-92, 1978.

Eggler, D. H., Solubility of major and trace elements in mantle metasomatic fluids: experimental constraints, in Mantle Metasomatism, edited by M. A. Menzies and C. J. Hawkesworth, pp. 21-41, Academic, San Diego, Calif., 1987.

EMSLAB Group. The EMSLAB electromagnetic sounding experiment, Eos Trans. AGU, 69, (7), 89, 98-99, 1988.

Etheridge, M. A., V. J. Wall, and R. H. Vernon, The role of the fluid phase during regional metamorphism and deformation, J. Metamorph. Geol., 1, 205-226, 1983.

Filloux, J. H., Magnetotelluric experiment over the ROSE area, $J$. Geophys. Res., 87, 8364-8378, 1982.

Filloux, J. H., Instrumentation and experimental methods for oceanic studies, in Geomagnetism, 1, edited by J. A. Jacobs, pp. 143-248, Academic, San Diego, Calif., 1987.

Fyfe, W. S., and A. R. McBimey, Subduction and the structure of andesitic volcanic belts, Am. J. Sci., 275-A, 285-297, 1975.

Gough, D. I., Electromagnetic geophysics and global tectonics, $J$. Geophys. Res., 88, 3367-3378, 1983.

Gough, D. I., D. McA. McKirdy, D. V. Woods, and H. Geiger, Conductive structures and tectonics beneath the EMSLAB land array, J. Geophys. Res., this issue.

Guffanti, M. and C. S. Weaver, Distribution of late Cenozoic volcanic vents in the Cascade Range: Volcanic arc segmentation and regional tectonic considerations, J. Geophys. Res., 93, 6513-6529, 1988.

Hermance, J. F., S. Lusi, W. Slocum, G. A. Neumann, and A. W. Green, $\mathrm{J}_{\mathrm{r} . \text {, }}$ A high density remote reference magnetic variation profile in the Pacific Northwest of North America, Phys. Earth Planet. Inter., in press, 1989.

Hughes, S. S., and E. M. Taylor, Geochemistry, petrogenesis, and tectonic implications of central High Cascades mafic platform lavas, Geol. Soc. Am. Bull., 97, 1024-1036, 1986.

Humphris, S. E., and G. Thompson, Hydrothermal alteration of oceanic basalts by seawater, Geochim. Cosmochim. Acta, 42, 107-125, 1978.

Hyndman, R. D., Dipping seismic reflectors, electrically conductive zones, and trapped water in the crust over a subducting plate, $J$. Geophys. Res., 93, 13,391-13,405,1988.

Ito, E., D. M. Harris, and A. T. Anderson, Jr., Alteration of oceanic crust and geologic cycling of chlorine and water, Geochim. Cosmochim. Acta, 47, 1613-1624, 1983.

Jiracek, G. R., J. H. Curtis, J. Ramirez, M. Martinez, and J. Romo, Twodimensional magnetotelluric inversion modeling of the EMSLAB Lincoln Line, J. Geophys. Res., this issue.

Jones, A. G., The problem of current-channeling: a critical review, Geophys. Surv., 6, 79-122, 1983.

Kariya, K .A., Limitations of the magnetotelluric method as applied to the Pioche-Marysvale trend, Utah, M. S. thesis, 56 pp., University of Utah, Salt Lake City, 1986.

Karsten, J. L., and J. R. Delaney, Hot spot-ridge crest convergence in the northeast Pacific, J. Geophys. Res., 94, 700-712, 1989.

Keach, R. W., II, Oliver, L. D. Brown, and S. Kaufman, Cenozoic active margin and shallow Cascades structure: COCORP results from westem Oregon, Geol. Soc. Am. Bull., 101, 783-794, 1989.

Kirby, S. H., Rheology of the lithosphere, Rev. Geophys., 21, 1458$1487,1983$.

Kulm, L. D., R. von Huene, et al., Sites 174 and 175, Initial. Rep. Deep Sea Drill. Proj., 18, 7-212, 1973.

Kulm, L. D., et al., Oregon subduction zone: venting, fauna, and carbonates, Science, 231, 561-566, 1986.

Kurtz, R. D., J. M. DeLaurier, and J. C. Gupta, A magnetotelluric sounding across Vancouver Island detects the subducting Juan de Fuca plate, Nature, 321, 596-599, 1986.

Langston, C. A., Corvallis, Oregon, crustal and upper mantle receiver structure from teleseismic $P$ and $S$ waves, Bull. Seismol. Soc. Am., 67, 713-724, 1977.

Larsen, J. C., Low frequency (0.1-6.0 cpd) electromagnetic study of the deep mantle electrical conductivity beneath the Hawaiian Islands, Geophys. J. R. Astron. Soc., 43, 14-56, 1975.
Law, L. K., and J. P. Greenhouse, Geomagnetic variation sounding of the asthenosphere beneath the Juan de Fuca ridge, J. Geophys. Res., 86, 967-978, 1981.

Lewis, T. J., W. H. Bentkowski, E. E. Davis, R. D. Hyndman, J. G. Souther, and J. A. Wright, Subduction of the Juan de Fuca plate: Thermal consequences, J. Geophys. Res., 93, 15,207-15,225, 1988. Livelybrooks, D. W., W. W. Clingman, J. T. Rygh, S. A. Urquhart, and H. S. Waff, A magnetotelluric study of the High Cascades graben in central Oregon, $J$. Geophys. Res., this issue.

Moore, J. C., et al., Expulsion of fluids from depth along a subductionzone decollement horizon, Nature, 326, 785-788, 1987.

Mysen, B. O., and I. Kushiro, Compositional variations of coexisting phases with degree of melting of peridotite in the upper mantle, Am. Mineral., 62, 843-865, 1977.

Oldenburg, D. W., K. P. Whittall, and R. L. Parker, Inversion of ocean bottom magnetotelluric data revisited, J. Geophys. Res., 89, 1829 $1833,1984$.

Olhoeft, G. R., Electrical properties of rocks, in Physical Properties of Rocks and Minerals, McGraw-Hill/CINDAS Data Ser. on Mater. Properties, vol. II-2, edited by Y. S. Touloukian and C. Y. Ho, pp. 57-297, McGraw-Hill, New York, 1981.

Oxburgh, E. R., Heat flow and magma genesis, in Physics of Magmatic Processes, pp. 161-200, edited by R. B. Hargraves, Princeton University Press, Princeton, N.J., 1980.

Parker, R. L., Understanding inverse theory, Annu. Rev. Earth Planet. Sci., 5, 35-64, 1977.

Priest, G. R., N. M. Woller, G. L. Black, and S. H. Evans, Overview of the geology of the central Oregon Cascades Range, in Geology and Geothermal Resources of the Central Oregon Cascade Range, edited by G. R. Priest and B. F. Vogt, Oreg. Dep. of Geol. Miner. Ind. Spec. Pap., 14, 2-28, 1983.

Priest, G. R., N. M. Woller, and M. L. Ferns, Geologic map of the Breitenbush River area, Linn and Marion Counties, Oregon, Map GMS-46, Oreg. Dep. of Geol. Miner. Ind., Portland, 1987.

Ranganayaki, R. P., and T. R. Madden, Generalized thin sheet analysis in magnetotellurics: An extension of Price's analysis, Geophys. J. $R$. Astron. Soc., 60, 445-457, 1980.

Rasmussen, J., and G. Humphries, Tomographic image of the Juan de Fuca plate beneath Washington and western Oregon using teleseismic $P$-wave travel times, Geophys. Res. Lett., 15, 1417-1420, 1988.

Riddihough, R. P., and D. A. Seeman, Gravity anomaly map of the Juan de Fuca plate, Map JFP-8, Can. Dep. of Energy, Mines and Resour., Ottawa, 1982

Riddihough, R. P., C. Finn, and R. Couch, Klamath-Blue Mountain lineament, Oregon, Geology, 14, 528-531, 1986.

Roberts, R. G., The deep electrical structure of the Earth, Geophys. J. R. Astron. Soc., 85, 683-700, 1986.

Sato, H., I. S. Sacks, T. Murase, and C. M. Scarfe, Thermal structure of the low velocity zone derived from laboratory and seismic investigations, Geophys. Res. Lett., 15, 1227-1230, 1988.

Shankland, T. J., and M. E. Ander., Electrical conductivity, temperatures, and fluids in the lower crust, J. Geophys. Res., 88, 9475-9484, 1983.

Shankland, T. J., R. J. O'Connell, and H. S. Waff, Geophysical constraints on partial melt in the upper mantle, Rev. Geophys., 198 394-406, 1981.

Smith, G. A., and E. M. Taylor, The Central Oregon High Cascades graben: What? Where? When?, Geotherm. Resour. Counc. Trans., 7, 275-278, 1983.

Smith, G. A., L. W. Snee, and E. M. Taylor, Stratigraphic, sedimentological, and petrological record of late Miocene subsidence of the central Oregon High Cascades, Geology, 15, 389-392, 1987.

Snavely, P. D., Jr., Tertiary geologic framework, neotectonics, and petroleum potential of the Oregon-Washington continental margin, in Geology and Resource Potential of the Continental Margin of Western North America and Adjacent Ocean Basins - Beaufort Sea to Baja California, Earth Sci. Ser., vol. 6, edited by D. W. Scholl, A. Grantz, and J. G. Vedder, pp. 305-335, Circum-Pacific Council for Energy and Mineral Resources vol. 6, Houston, Tex., 1987.

Stanley, W. D., G. S. Fuis, and W. D. Mooney, Details of crustal structure in the Cascade Range and surrounding regions from seismic and magnetotelluric data, in Geological, Geophysical and Tectonic Setting of the Cascade Range, U.S. Geol. Surv. Open File Rep. 89 178, pp. 31-73, edited by L. J. P. Muffler, C. S. Weaver, and D. D. Blackwell, 1989.

Tyburczy, J. A., and H. S. Waff, Electrical conductivity of molten basalt and andesite to 25 kilobars pressure: Geophysical significance and 
implications for charge transport and melt structure: $J$. Geophys. Res., 88, 2413-2430, 1983.

Verplanck, E. P., and R. A. Duncan, Temporal variations in plate convergence and eruption rates in the Westem Cascades, Oregon, Tectonics, 6, 197-209, 1987.

von Bargen, N., and H. S. Waff, 1986, Permeabilities, interfacial areas, and curvatures of partially molten systems: Results of numerical computations of equilibrium microstructures, J. Geophys. Res., 91, 9261-9276, 1986.

Waff, H. S., J. T. Rygh, D. W. Livelybrooks, and W. W. Clingman, Results of a magnetotelluric traverse across westem Oregon: Crustal resistivity structure and the structure of the Juan de Fuca plate, Earth Planet. Sci. Lett., 87, 313-324, 1988.

Wannamaker, P. E., Resistivity structure of the Northem Basin and Range, in The Role of Heat in the Development of Energy and Mineral Resources in the Northern Basin and Range Province, Geotherm. Resour. Counc. Spec. Rep. 13, 345-362, 1983.

Wannamaker, P. E., Electrical conductivity of water-undersaturated crustal melting, J. Geophys. Res., 91, 6321-6327, 1986.

Wannamaker, P. E., On thin-layer telluric modeling of magnetotelluric responses, Geophysics, in press, 1989.

Wannamaker, P. E., G. W. Hohmann, and S. H. Ward, Magnetotelluric responses of three-dimensional bodies in layered earths, Geophysics, 49, 1517-1533, 1984.

Wannamaker, P. E., J. A. Stodt, and L. Rijo, Two-dimensional topographic responses in magnetotellurics modeled using finite elements, Geophysics, 51, 2131-2144, 1986.

Wannamaker, P. E., J. A. Stodt, and L. Rijo, A stable finite element solution for two-dimensional magnetotelluric modeling, Geophys. $J$. $R$. Astron. Soc., 88, 277-296, 1987.

Wannamaker, et al., Magnetotelluric observations across the Juan de Fuca subduction system in the EMSLAB project, J. Geophys. Res., this issue.

Wells, F. G., and D. L. Peck. Geologic map of Oregon west of the 121st meridian, U. S. Geol. Surv. Map I-325, 1964.

Wyllie, P. J., Magmas and volatile components, Am. Mineral., 64, 469$500,1979$.

Wyllie, P. J., Magma genesis, plate tectonics, and chemical differentiation of the earth, Rev. Geophys., 26, 370-404, 1988.
Young, P. D., and C. S. Cox, Electromagnetic active source sounding near the East Pacific Rise, Geophys. Res. Lett., 8, 1043-1046, 1981.

Young, C. T., and M. R. Kitchen, A magnetotelluric profile in the Coast Range of Oregon, J. Geophys. Res., this issue.

Young, C. T., J. R. Booker, R. Femandez, G. R. Jiracek, M. Martinez, J. C. Rodgers, J. A. Stodt, H. S. Waff, and P. E. Wannamaker, Verification of five magnetotelluric systems in the mini-EMSLAB experiment, Geophysics, 53, 553-557, 1988.

J. R. Booker, Geophysics Dept., AK-50, University of Washington, Seattle, WA 98195.

A. D. Chave, AT\&T Bell Laboratories, Rm 1E-444, 600 Mountain Ave., Murray Hill, NJ 07974.

J. H. Filloux, Scripps Institution of Oceanography, MS A030, University of Califomia at San Diego, La Jolla, CA 92093.

A. G. Jones, Lithospheric Geophysics, Geological Survey of Canada, 1 Observatory Crescent, Ottawa, Ontario, Canada, K1A 0Y3.

L. K. Law, Pacific Geoscience Center, Geological Survey of Canada, P. O. Box 6000, Sidney, British Columbia, Canada V8L 4BZ.

H. S. Waff, Department of Geology, University of Oregon, Eugene, OR 97403.

P. E. Wannamaker, University of Utah Research Institute, 391-C Chipeta Way, Salt Lake City, UT 84108.

(Received October 28, 1988; revised March 29, 1989; accepted April 3, 1989.) 


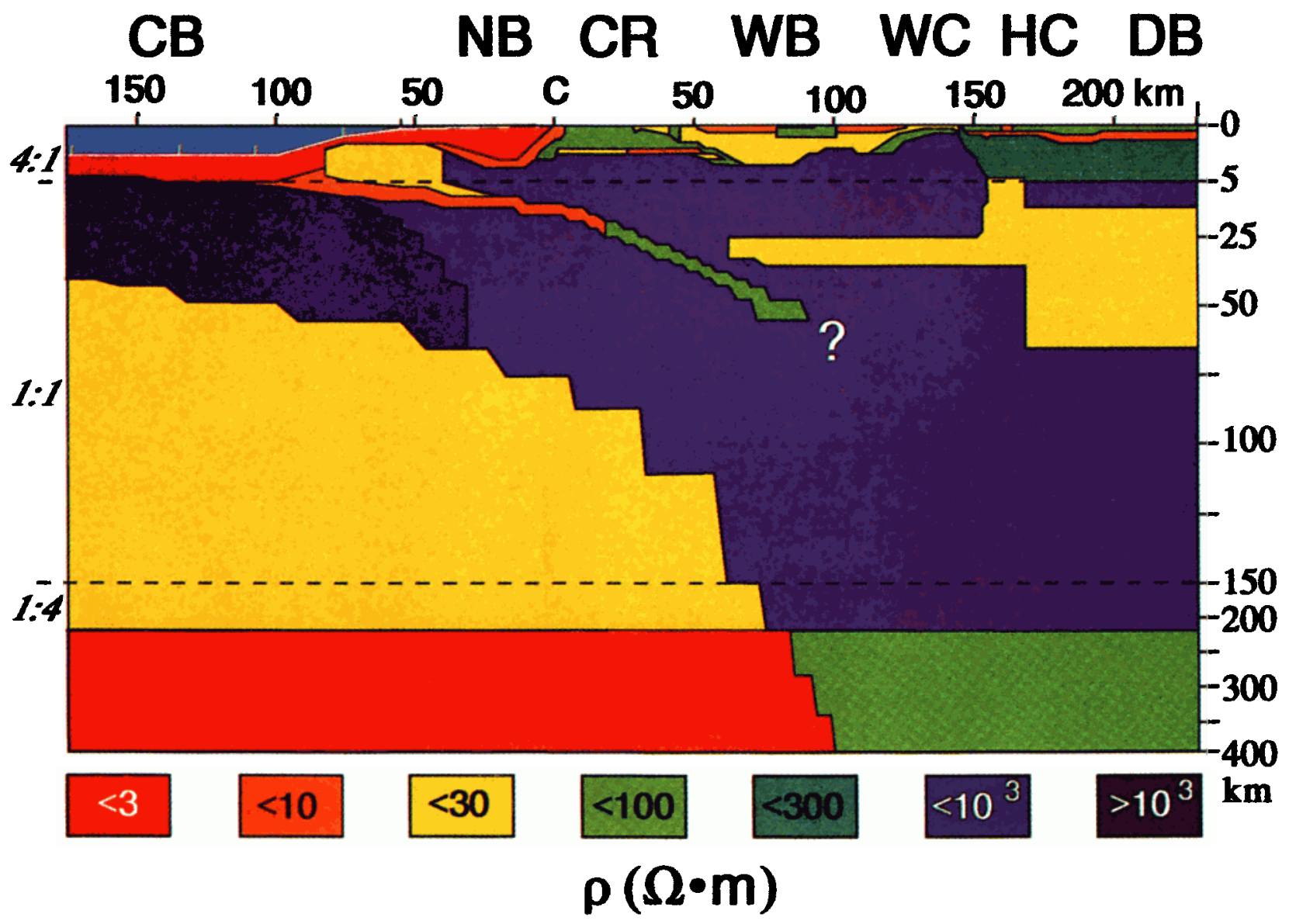

Plate 1. [Wannamaker et al.]. East-west resistivity cross section derived from forward modeling of MT data along the Lincoln Line. Section preserves details of the finite element mesh geometry but resistivities have been grouped in halfdecade intervals for color display. Seafloor portion of the model is shown only to $175 \mathrm{~km}$ offshore, beyond which variations are minor. Note changes in verical exaggeration, labelled on the left, at $5 \mathrm{~km}$ and $150 \mathrm{~km}$ depth. Important physiographic regions crossed include the Cascadia Basin (CB), Newport Basin (NB), Coast Range (CR), Willamette Basin (WB), Westem Cascades (WC), High Cascades (HC), and the Deschutes Basin (DB). 


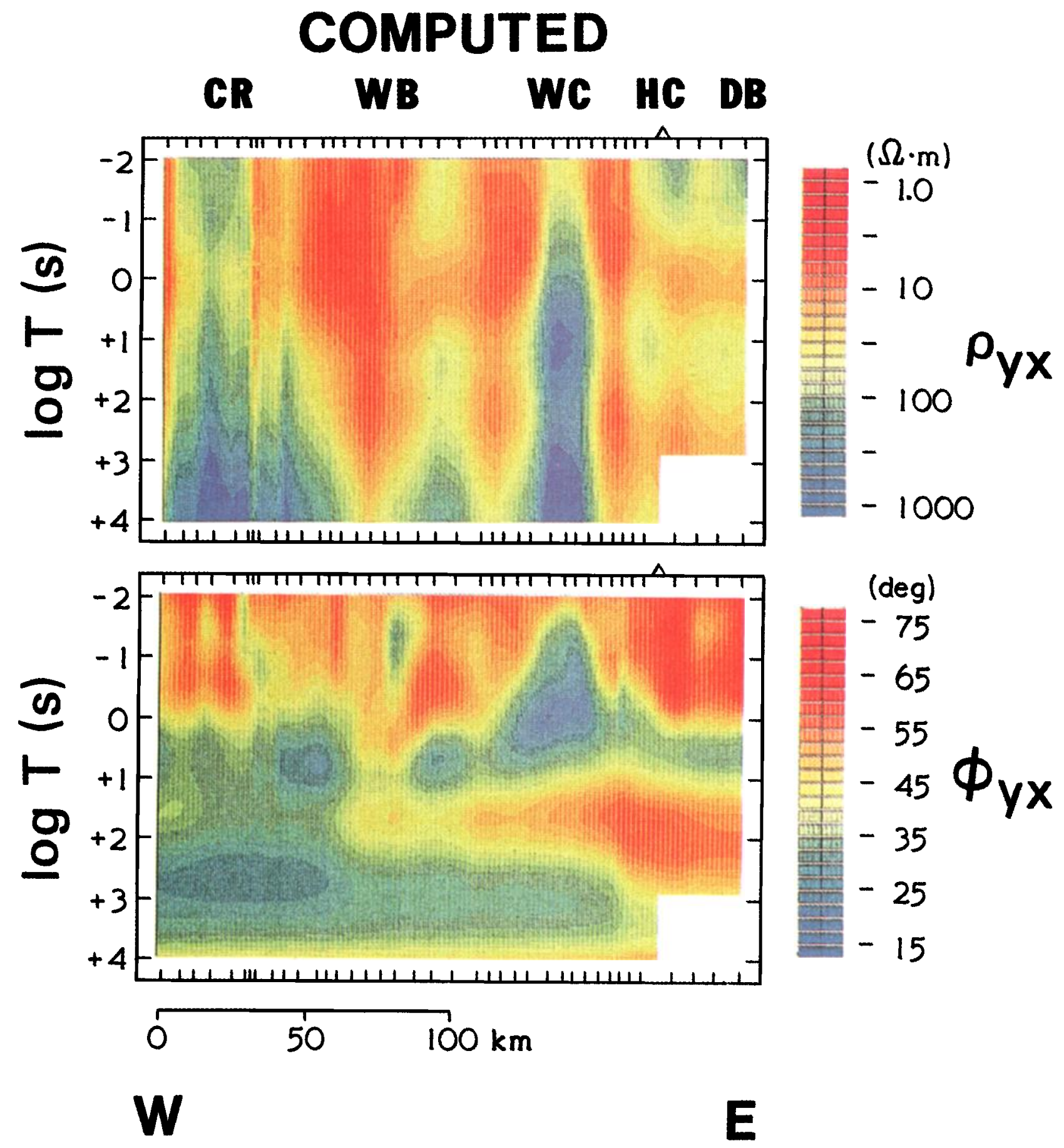

Plate 2. [Wannamaker et al.]. Pseudosections of transverse magnetic apparent resistivity $\rho_{y x}$ and impedance phase $\phi_{y x}$ computed along the landward portion of the Lincoln Line. 


\section{COMPUTED}
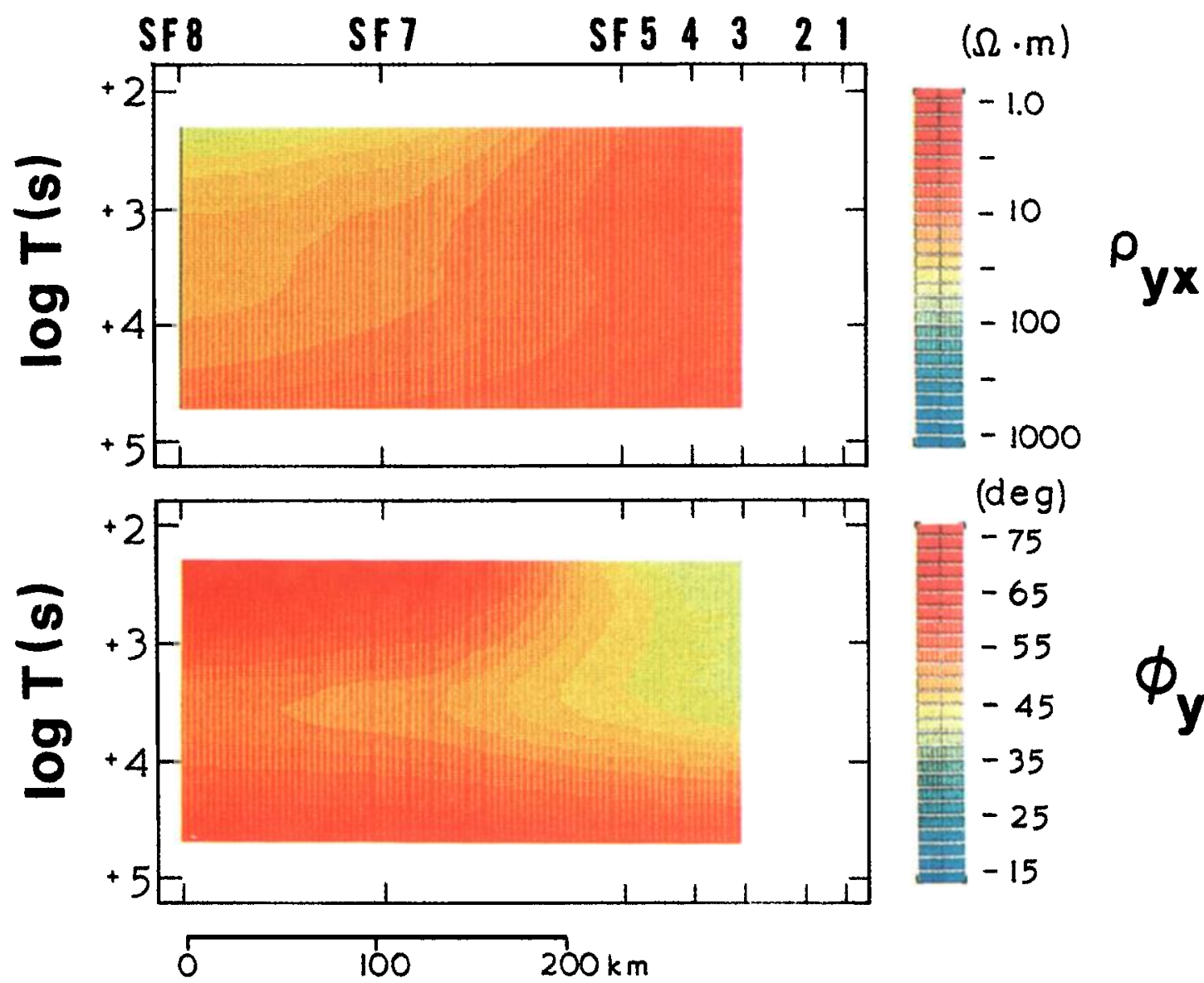

E

Plate 3. [Wannamaker et al.] . Pseudosections of transverse magnetic apparent resistivity $\rho_{y x}$ and impedance phase $\phi_{y x}$ computed along the seafloor portion of the Lincoln Line. Note differences in horizontal scale and period range between land and seafloor resuiks. 


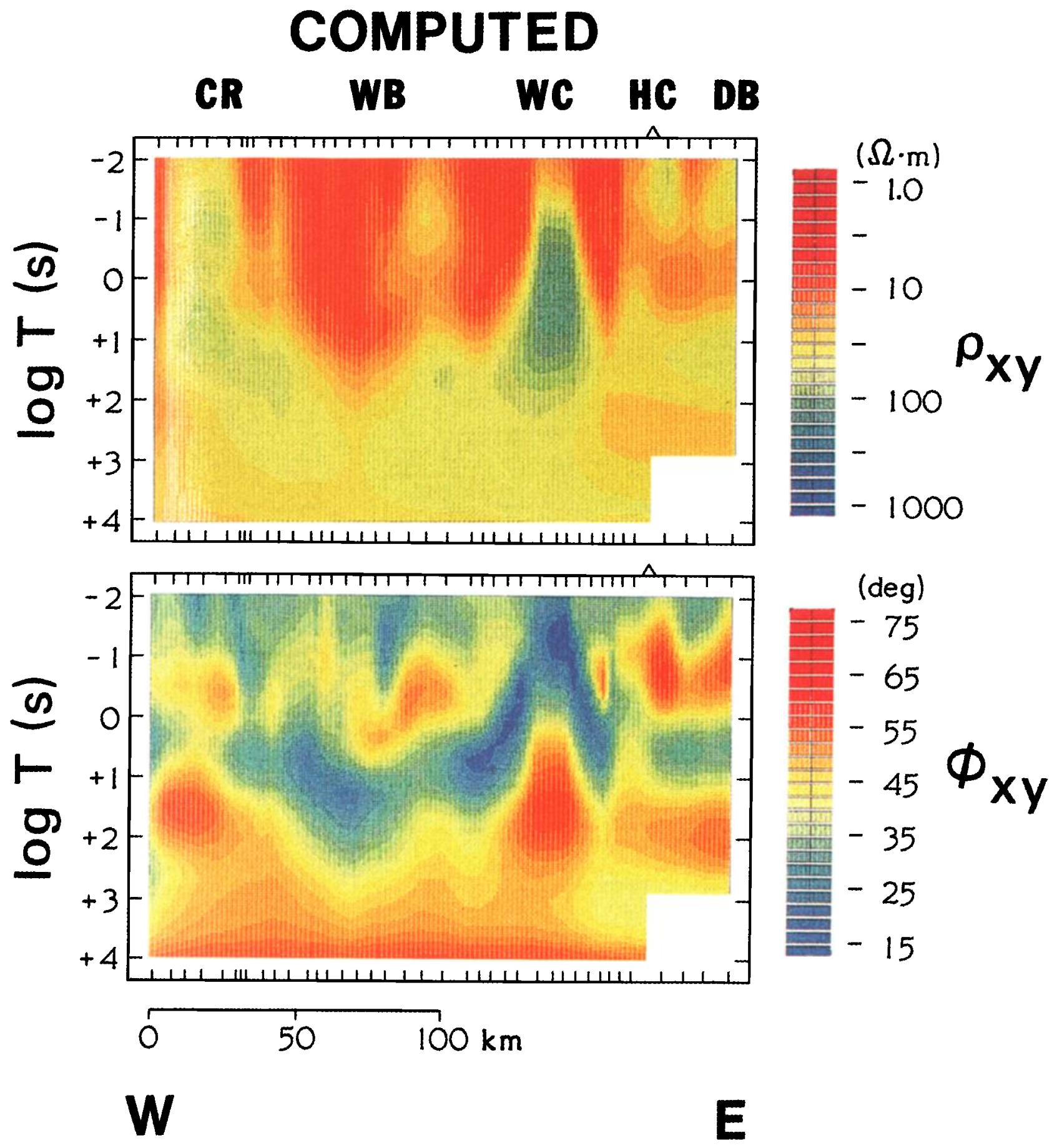

Plate 4. [Wannamaker et al.]. Pseudosections of transverse electric apparent resistivity $\rho_{x y}$ and impedance phase $\phi_{x y}$ computed along the landward portion of the Lincoln Line. 


\section{COMPUTED}

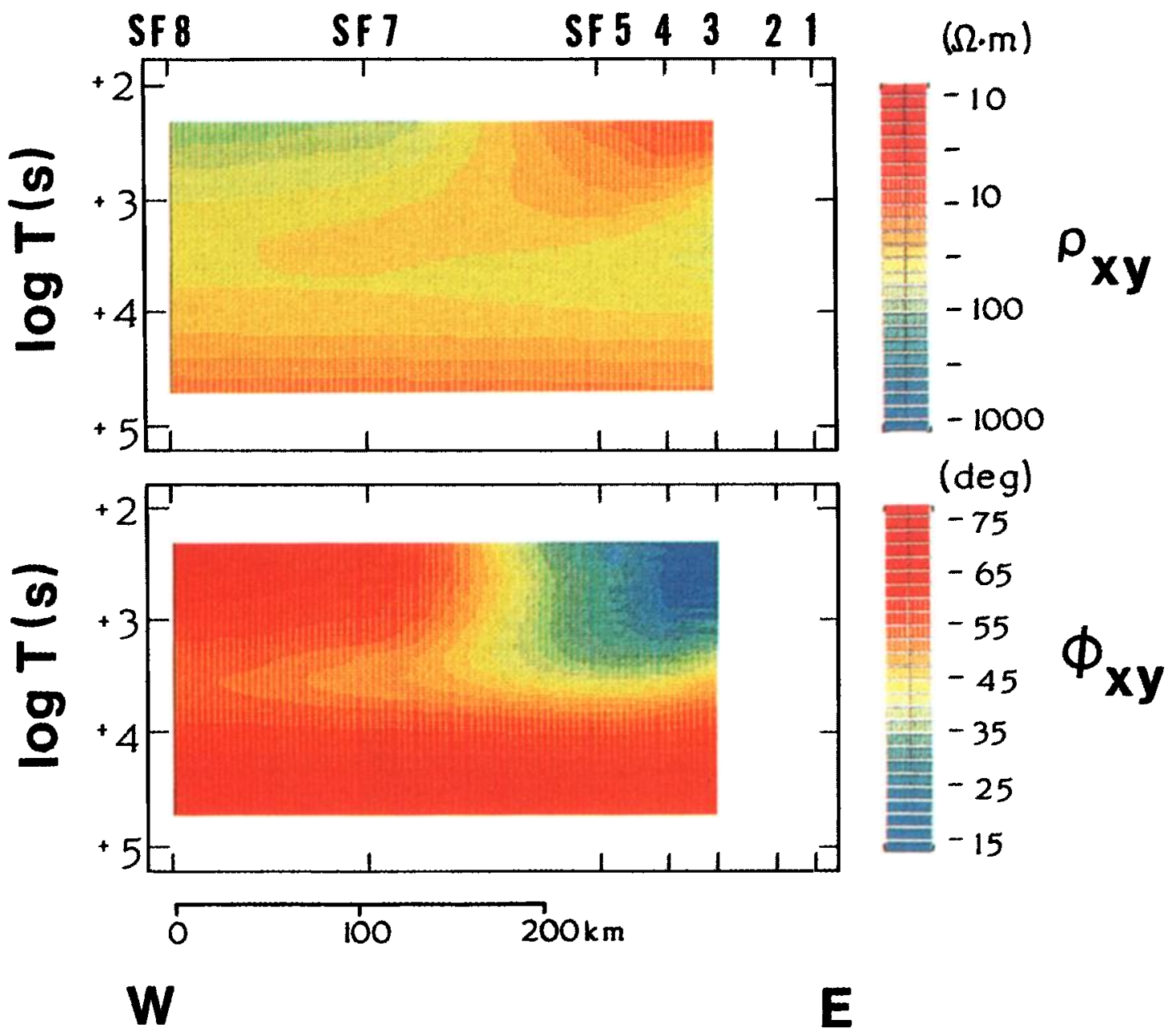

Plate 5. [Wannamaker et al.]. Pseudosections of transverse electric apparent resistivity $\rho_{x y}$ and impedance phase $\phi_{x y}$ computed along the seafloor portion of the Lincoln Line. Note differences in horizontal scale and period range between land and seafloor results. 


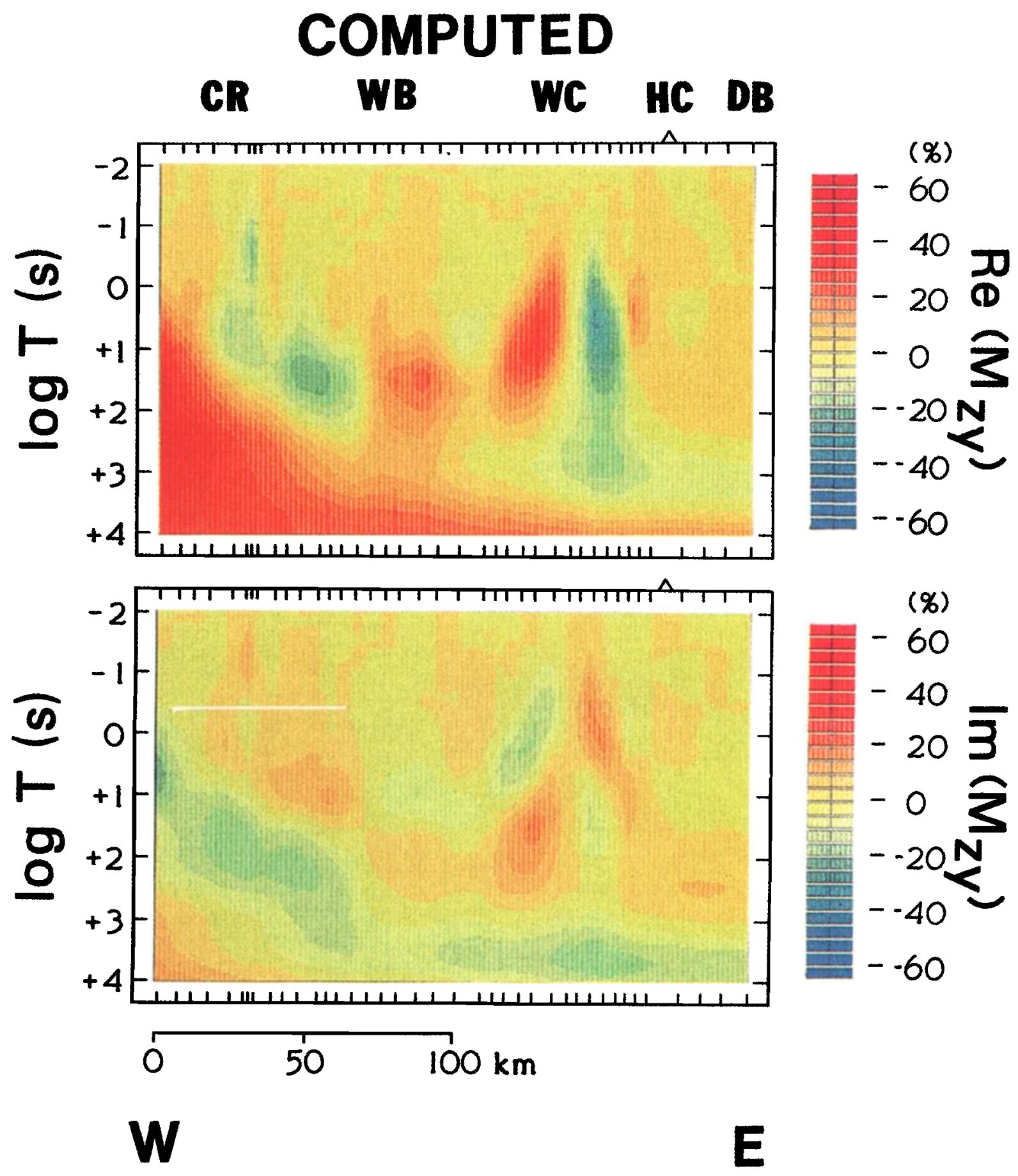

Plate 6. [Wannamaker et al.]. Pseudosections of vertical magnetic field transfer element $M_{z y}$, real and imaginary parts, computed along the landward portion of the Lincoln Line. 


\section{COMPUTED}
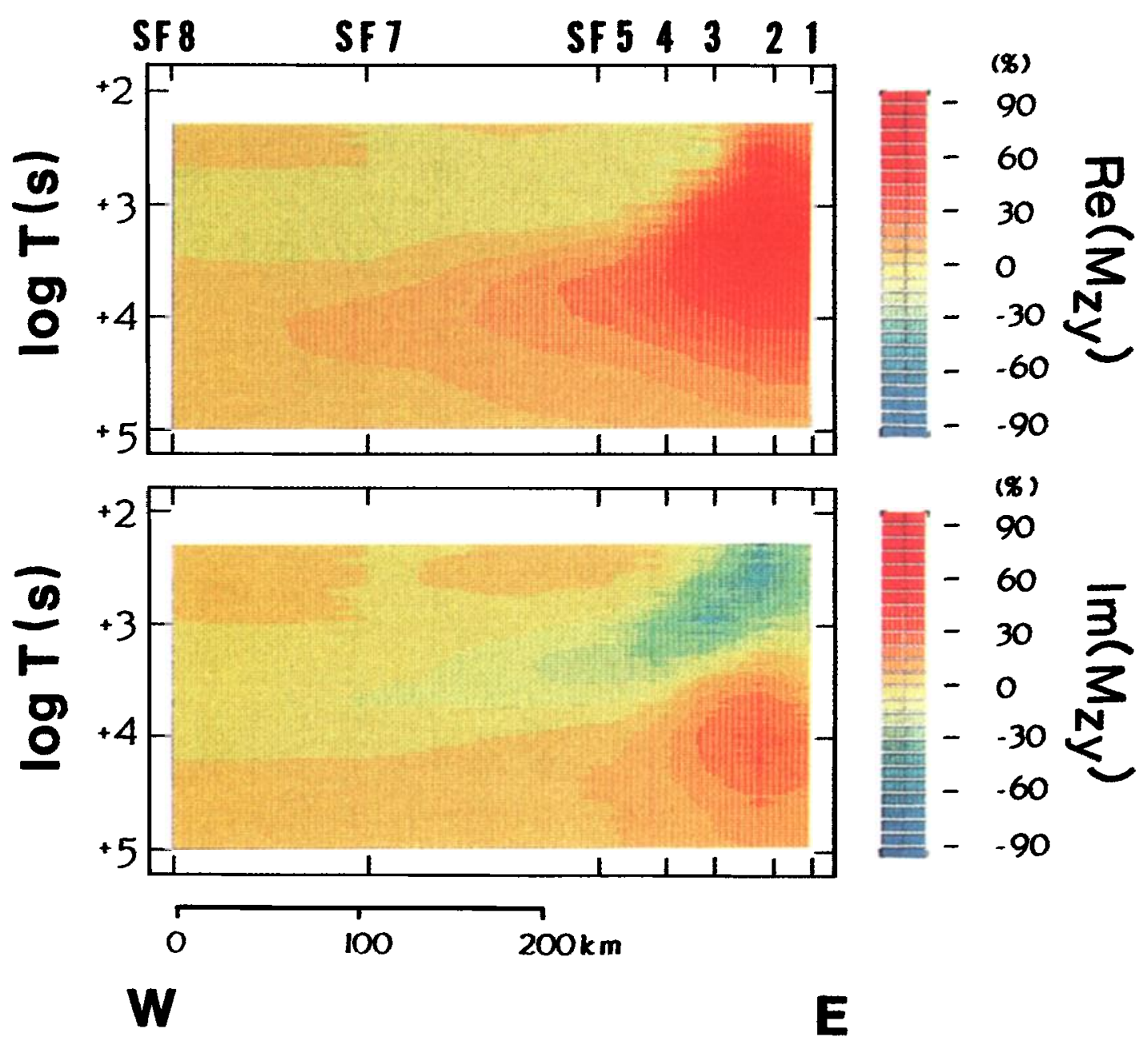

Plate 7. [Wannamaker et al.]. Pseudosections of vertical magnetic field transfer element $\boldsymbol{M}_{x y}$, real and imaginary parts, computed along the seafloor portion of the Lincoln Line. Note differences in horizontal scale, period range, and contour interval between land and seafloor results. 